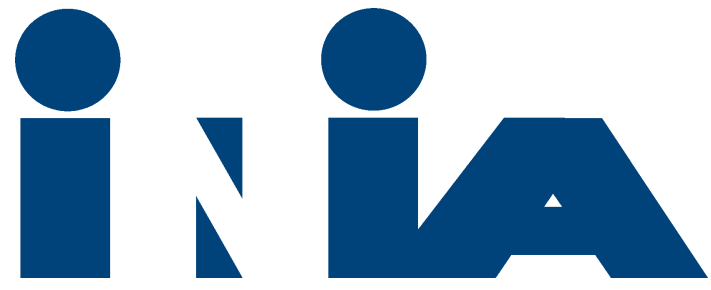

INSTITUTO NACIONAL DE INVESTIGACIÓN AGROPECUARIA

URUGUAY
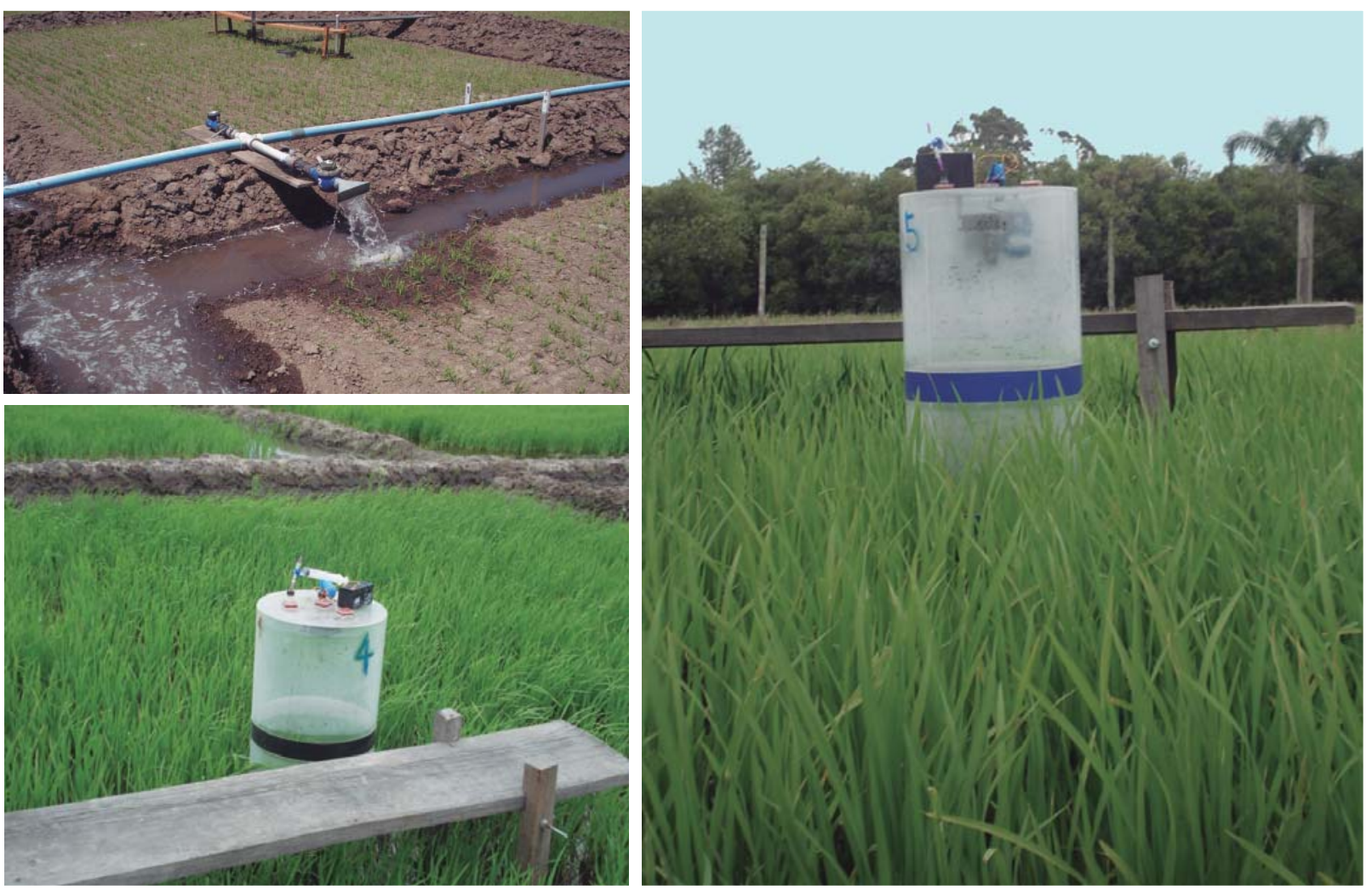

CUANTIFICACIÓN DE

EMISIONES DE METANO Y

ÓXIDO NITROSO BAJO DOS

MANEJOS DEL RIEGO

CONTRASTANTES EN EL

CULTIVO DE ARROZ

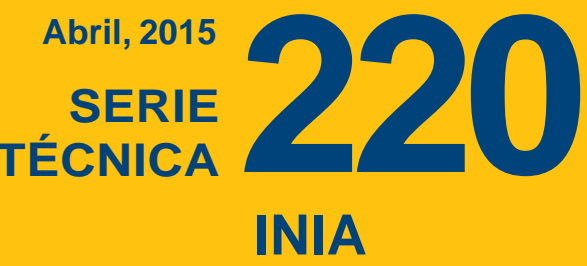




\title{
CUANTIFICACIÓN DE EMISIONES DE METANO Y ÓXIDO NITROSO BAJO DOS MANEJOS DEL RIEGO CONTRASTANTES EN EL CULTIVO DE ARROZ
}

\author{
Autores: Ma. Cristina Capurro ${ }^{1}$ \\ Silvana Tarlera ${ }^{2}$ \\ Pilar Irisarri ${ }^{3}$ \\ Guillermina Cantou ${ }^{4}$ \\ Sara Riccetto 5 \\ Ana Fernández 6 \\ Álvaro Roel ${ }^{7}$
}

${ }^{1}$ Ing.Agr. Programa Nacional de Arroz, INIA Treinta y Tres.

${ }^{2}$ Química Farm. PhD. Departamento de Biociencias, Facultad de Química, Universidad de la Republica. UDELAR.

${ }^{3}$ Ing. Agr. PhD. Departamento de Biología vegetal, Facultad de Agronomía, Universidad de la República. UDELAR.

${ }^{4}$ Ing. Agr. Programa Nacional de Sustentabilidad Ambiental, INIA Treinta y Tres.

${ }^{5}$ Ing.Agr. Programa Nacional de Arroz, INIA Treinta y Tres.

${ }^{6}$ Química Farm. PhD. Departamento de Biociencias, Facultad de Química, Universidad de la Republica. UDELAR.

${ }^{7}$ Ing. Agr. Msc. PhD. Programa Nacional de Arroz, INIA Treinta y Tres. 
Título: CUANTIFICACIÓN DE EMISIONES DE METANO Y ÓXIDO NITROSO BAJO DOS MANEJOS DEL RIEGO CONTRASTANTES EN EL CULTIVO DE ARROZ

Autores: Ma. Cristina Capurro

Silvana Tarlera

Pilar Irisarri

Guillermina Cantou

Sara Riccetto

Ana Fernández

Álvaro Roel

Serie Técnica $N^{\circ} 220$

(C) 2015, INIA

Editado por la Unidad de Comunicación y Transferencia de Tecnología del INIA Andes 1365, Piso 12. Montevideo - Uruguay

http://www.inia.uy

Quedan reservados todos los derechos de la presente edición. Esta publicación no se podrá reproducir total o parcialmente sin expreso consentimiento del INIA. 


\section{I nstituto Nacional de I nvestigación Agropecuaria}

\section{Integración de la Junta Directiva}

Ing. Agr., MSc., PhD. Álvaro Roel - Presidente

D.M.T.V., PhD. J osé Luis Repetto - Vicepresidente
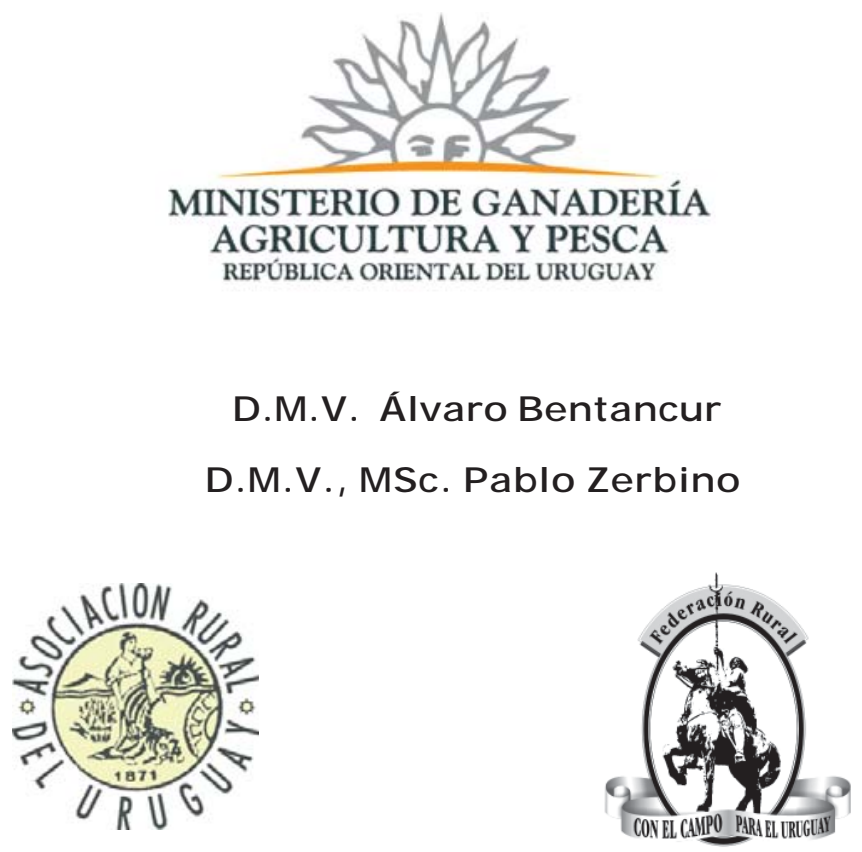

Ing. Agr. J oaquín Mangado

Ing. Agr. Pablo Gorriti
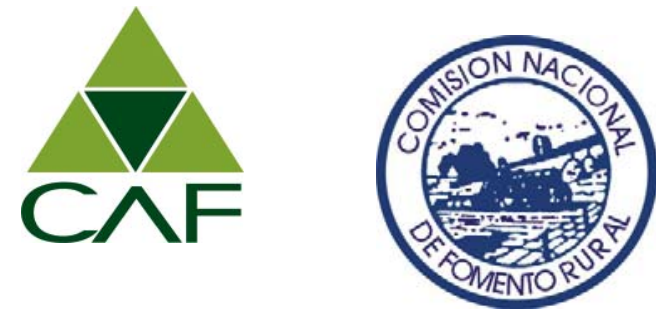



\section{CONTENIDO}

Página

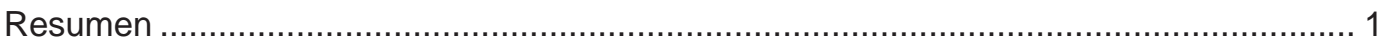

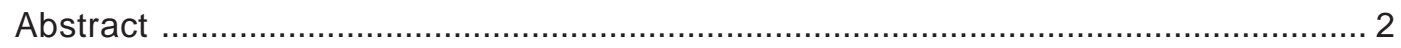

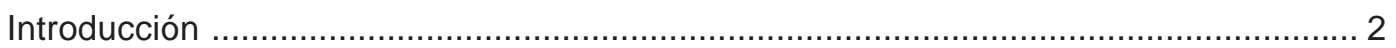

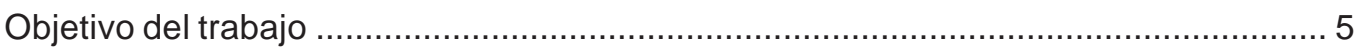

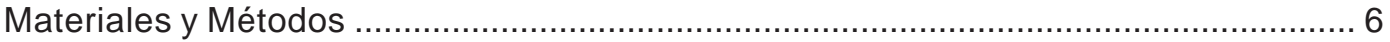

Medición del agua de riego y parámetros del cultivo ..................................................... 7

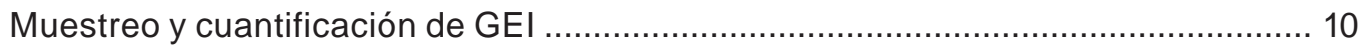

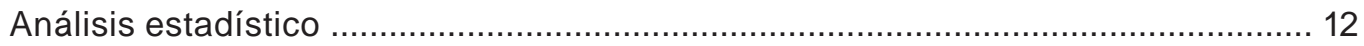

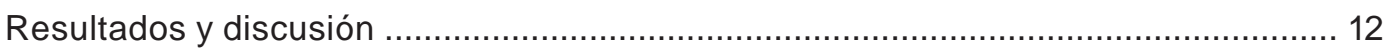

Caracterización climática de las zafras analizadas .................................................. 12

Evolución del crecimiento y fenología del cultivo .................................................... 14

Patrones estacionales de emisión de metano y óxido nitroso .................................... 15

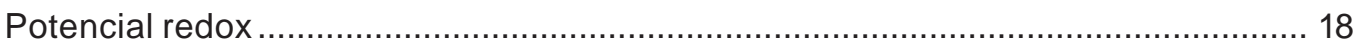

Productividad y eficiencia del uso del agua ........................................................ 22

Potencial de calentamiento global en relación a los tratamientos de riego ............... 23

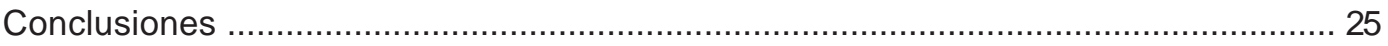

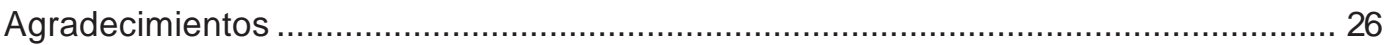

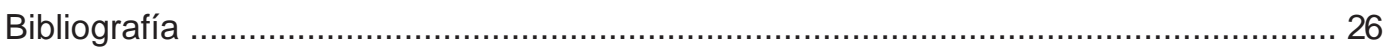

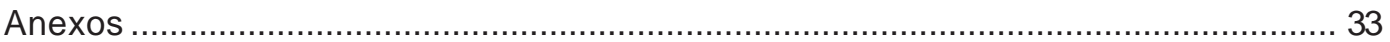





\section{ÍNDICE DE CUADROS}

Página

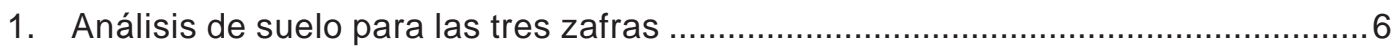

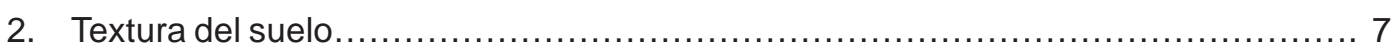

3. Calendario agronómico para las tres zafras ….....................................................

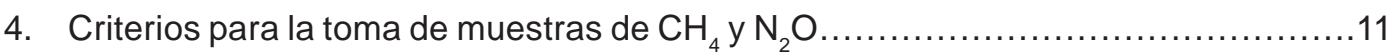

5. Precipitaciones $(\mathrm{mm})$ desde siembra a cosecha para las tres zafras...............13

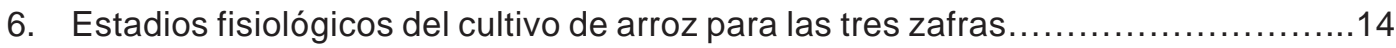

7. Efecto de los tratamientos de riego sobre la fenología y días de riego del cultivo

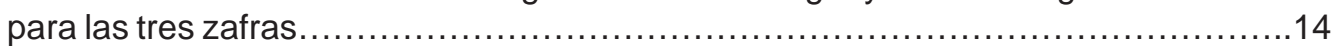

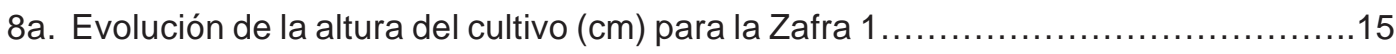

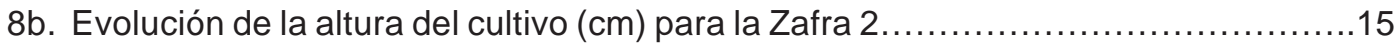

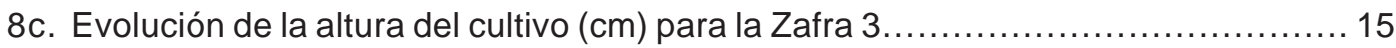

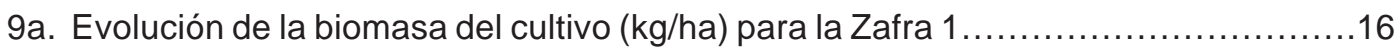

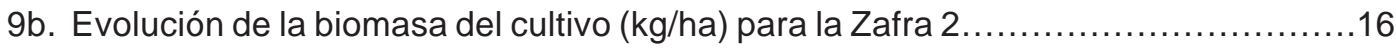

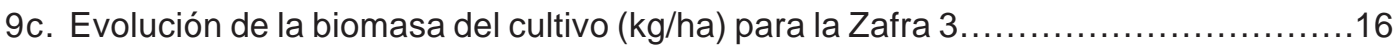

10. Rendimiento del cultivo y emisiones de metano y óxido nitroso según zafra..........17

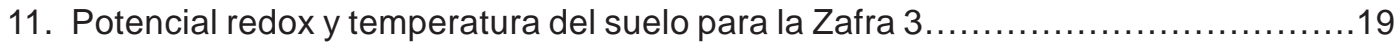

12. Consumo y productividad del agua para el cultivo de arroz bajo los dos tratamientos y en las tres zafras

13. Contribución del metano y óxido nitroso al potencial de calentamiento global (PCG) en cada tratamiento de riego para las tres zafra ........................................24

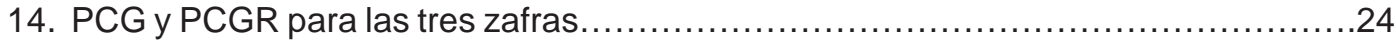

Anexos

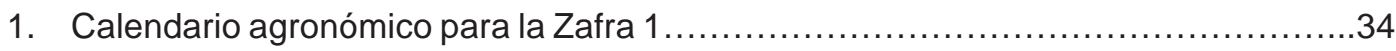

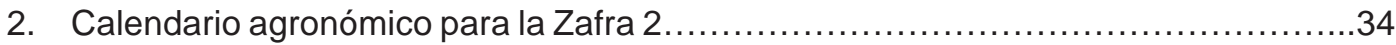

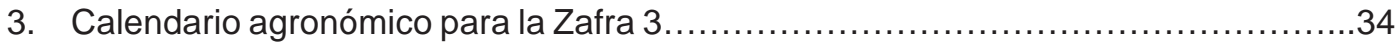

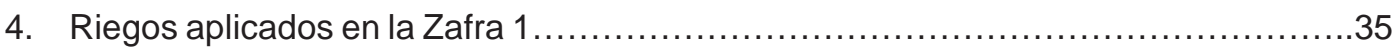

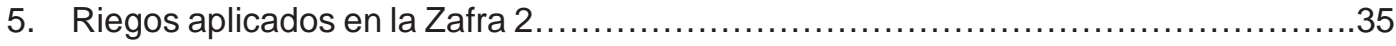

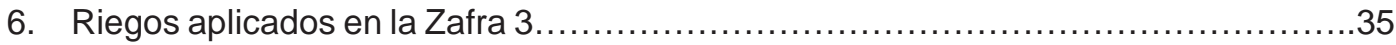

7. Heliofanía promedio en torno al periodo crítico del cultivo (+/- 20 días del $50 \%$ de floración) para la Zafra 1 
8. Heliofanía promedio en torno al periodo crítico del cultivo (+/- 20 días del 50\% de floración) para la Zafra 2

9. Heliofanía promedio en torno al periodo crítico del cultivo (+/- 20 días del $50 \%$ de floración) para la Zafra.....

10. Temperatura mínima y temperatura media promedio en torno al período crítico del cultivo (+/- 20 del $50 \%$ de floración) para la Zafra 1.

11. Temperatura mínima y temperatura media promedio en torno al período crítico del cultivo (+/- 20 del 50\% de floración) para la Zafra 2

12. Temperatura mínima y temperatura media promedio en torno al período crítico del cultivo (+/- 20 del $50 \%$ de floración) para la Zafra 3 


\section{ÍNDICE DE FIGURAS}

Página

1. Representación del ciclo del cultivo para los tratamientos de inundación continua (IC 30) y riego con déficit controlado (RR)

2a. Evolución de la temperatura media diaria para las tres zafras estudiadas 13

2b. Precipitación diaria para las tres zafras estudiadas... 13

3a. Emisión de metano para el tratamiento IC 30 en las tres zafras analizadas 16

3b. Emisión de metano para el tratamiento RR en las tres zafras analizadas 17

4. Evolución del potencial redox para el tratamiento IC 30 y RR en la Zafra 3 19

5a. Emisión de óxido nitroso para el tratamiento IC30 en las tres zafras analizadas .. 21

5b. Emisión de óxido nitroso para el tratamiento RR en las tres zafras analizadas 21

6. Potencial de calentamiento global por $\mathrm{kg}$ de arroz producido para dos manejos del agua diferentes

Anexos

1. Evolución del contenido de agua en el suelo en el tratamiento RR para las tres zafras 



\section{CUANTIFICACIÓN DE EMISIONES DE METANO Y ÓXIDO NITROSO BAJO DOS MANEJOS DEL RIEGO CONTRASTANTES EN EL CULTIVO DE ARROZ}

Ma. Cristina Capurro ${ }^{1}$, Silvana Tarlera ${ }^{3}$ Pilar Irisarri², Guillermina Cantou ${ }^{1}$, Sara Riccetto ${ }^{1}$, Ana Fernández ${ }^{3}$ Álvaro Roel ${ }^{1}$

\section{RESUMEN}

El manejo del riego ha demostrado tener un impacto sobre las emisiones de metano $\left(\mathrm{CH}_{4}\right)$ y óxido nitroso $\left(\mathrm{N}_{2} \mathrm{O}\right)$ en el cultivo de arroz. El riego con déficit controlado, el cual disminuye el período bajo inundación, ha sido reportado como una importante herramienta para atenuar las emisiones de metano. Sin embargo este manejo del riego podría incrementar las emisiones de óxido nitroso y reducir el rendimiento. Por lo tanto, es importante analizar las posibles compensaciones entre las emisiones de gases de efecto invernadero (GEI) y la productividad. A lo largo de tres años dos manejos del riego contrastantes fueron evaluados con respecto a las emisiones totales de metano y óxido nitroso, rendimiento, consumo y productividad del agua. Los manejos de agua estudiados fueron el manejo tradicional que consistió en el establecimiento de la inundación a los 30 días después de la emergencia (IC30) en comparación con un riego restringido con déficit controlado que permitía el secado y mojado del suelo (RR). RR presentó una acumulación media de metano de $98,4 \mathrm{~kg} / \mathrm{ha} \mathrm{CH}_{4}$, que fueron un 55\% menores a los observados en IC 30 , mientras que no hubo diferencias significativas en las acumulaciones medias de óxido nitroso entre ambos tratamientos de riego. En dos de los años evaluados no hubo diferencias significativas de rendimiento entre los manejos del riego, mientras que el manejo RR presentó un rendimiento significativamente menor en uno de los años. No hubo diferencias en la totalidad de agua aplicada y en la productividad de la misma en dos de los años evaluados, mientras que el tratamiento IC30 presentó mayores niveles de agua aplicada y menor productividad del agua en uno de ellos. Estos resultados sugieren que el manejo del riego con déficit controlado (RR) puede ser una opción para reducir las emisiones GEI del cultivo de arroz. De todas formas, este manejo del riego puede comprometer el rendimiento del cultivo, determinando por lo tanto la importancia de la correcta evaluación de las incertidumbres y riesgos a la hora de promover su adopción por los productores.

Palabras clave: Gases de efecto invernadero, déficit controlado, Potencial de Calentamiento Global, riego restringido

${ }^{1}$ Instituto Nacional de Investigación Agropecuaria (INIA).

2Departamento de Biología Vegetal, Facultad de Agronomía, Universidad de la República (UDELAR).

${ }^{3}$ Cátedra de Microbiología, Departamento de Biociencias, Facultad de Química (UDELAR). 
ABSTRACT

Irrigation management has been shown to have an impact on methane $\left(\mathrm{CH}_{4}\right)$ and nitrous oxide $\left(\mathrm{N}_{2} \mathrm{O}\right)$ rice emissions. The controlled deficit irrigation, which reduces the period under flood, has been reported as an important tool to reduce methane emissions. However, this irrigation management could increase nitrous oxide emissions and reduce crop performance. Therefore, it is important to analyze the possible trade-offs between emissions of greenhouse gases (GHG) and productivity. Over three years, two contrasting irrigation managements were evaluated respect to total methane and nitrous oxide emissions, crop performance, water consumption and productivity. Two water managements were studied, a traditional management consisting in establishing flood at 30 days after emergence (IC30) and a restricted water management with a deficit controlled irrigation, which allows wetting and drying soil (RR). These results showed that RR had mean cumulative $\mathrm{CH}_{4}$ emission values of $98,4 \mathrm{~kg} / \mathrm{ha} \mathrm{CH}_{4}, 55 \%$ lower when compared to IC30 while no significant differences in nitrous oxide emissions were observed among treatments. No significant yield reduction between irrigation treatments was observed in two of the years, however RR management presented a significantly lower performance in one of the years. There was no difference in total water consumption and productivity in two of the three years evaluated, while IC30 presented higher levels of water consumption and lower water productivity in one of the three years. These results suggest that controlled deficit irrigation management (RR) may be an option to reduce GHG emissions from rice crops. Nevertheless, this irrigation management can compromise crop yield, thereby it is important to properly assess uncertainties and risks when promoting their adoption by farmers.

Keywords: Greenhouse Gases, controlled deficit irrigation, Global Warming Potential, restricted water management.

\section{INTRODUCCIÓN}

La legislación internacional inexorablemente aumentará las exigencias en materia de impacto ambiental, sustentabilidad y mitigación del cambio climático. Existe a su vez una creciente demanda por parte de los consumidores de alimentos por estar informados respecto a indicadores de inocuidad y de sustentabilidad ambiental (Frohmann y Olmos, 2013). Es previsible por lo tanto, que los asuntos ambientales y el combate del cambio climático se asocien cada vez más con la competitividad exportadora de bienes agropecuarios. Adicionalmente, intereses comerciales pueden expresarse detrás de consideraciones ambientales, llevando a amenazas de tipo para-arancelario e incluso arancelario (Oyhantçabal, 2010). El cambio climático se ha convertido no sólo en un problema ambiental con impactos a nivel social y de los ecosistemas, sino que tiene impac- to en la economía y ha trascendido al comercio internacional. En este sentido, para un país agroexportador como es Uruguay, resulta imprescindible trabajar de manera proactiva frente a las nuevas exigencias ambientales de los mercados internacionales (Becoña y Ordeig, 2013).

La huella de carbono $(\mathrm{HC})$ que los bienes y servicios producen en su ciclo de vida es una forma de exponer y asignar los respectivos costos climáticos y al mismo tiempo una posible restricción al comercio que el sector exportador podría enfrentar en el corto plazo (Becoña y Ordeig, 2013). Según Wiedmann y Minx (2007), la huella de carbono es una medida de las emisiones totales de dióxido de carbono que son causadas directa o indirectamente por una actividad o acumuladas durante las etapas de la vida de un producto. Dado el alto peso relativo de las emisiones gases de efecto invernadero (GEI) en la fase primaria de producción de los commo- 
dities, la huella de carbono resulta muy dependiente de la eficiencia de los procesos y de las tecnologías aplicadas a nivel predial. Particularmente la HC para el arroz, consiste en calcular y adicionar las emisiones de GEI a lo largo de toda la cadena arrocera (transporte de insumos - producción de insumos - fase primaria - fase industrial- transporte a destino - producto final). Estos valores son reportados generalmente en términos de $\mathrm{CO}_{2}$ equivalente/kg arroz elaborado. La bibliografía nacional e internacional indica que dentro de los componentes de mayor peso en la $\mathrm{HC}$ del arroz está el $\mathrm{CH}_{4}$ producido en la fase productiva (Becoña et al., 2014). Por lo tanto es muy importante generar información y obtener datos de emisiones locales a los efectos de los cálculos de la huella de carbono. En Uruguay se han identificado incertidumbres en las estimaciones actuales y en ese sentido, una de las prioridades para la investigación es el desarrollo de factores de emisión nacionales para óxido nitroso y metano en arroz (Oyhantçabal, 2010).

La medición de GEI es un paso fundamental para evaluar los impactos sobre el clima y a su vez evaluar posibles ineficiencias en los procesos de producción. Menores emisiones de GEI disminuyen o retardan los efectos del cambio climático y permitirían mantener las condiciones para desarrollar determinados cultivos locales durante un lapso de tiempo mas prolongado (Frohmann y Olmos, 2013).

La información sobre emisiones de GEI permite también identificar procesos o insumos que requieren ajustes o deben ser cambiados, para reducir la huella de carbono. Como consecuencia se producen mejoras en la eficiencia, se inducen mejoras en la innovacion de procesos, eficiencia en la utilización de recursos y por lo tanto reduciendo costos. Contar con procesos y productos que generen (Becoña y Ordeig, 2013), menos emisiones constituye un factor de diferenciación en los mercados internacionales; satisfaciendo requerimientos exigentes de sostenibilidad ambiental que fortalece y hace más competitivo el producto y su sello de calidad (Frohmann y Olmos, 2013).
Uruguay debe destacar el valor agregado ambiental de sus productos, diferenciarlos y asi acceder a mercados más exigentes (Oyhantcabal, 2010).

Existen múltiples opciones para reducir las emisiones de GEI a nivel mundial, las mismas implican cooperación internacional, estímulo de políticas nacionales y la creación de un mercado internacional del carbono y de mecanismos al respecto, que son llevados a cabo por la Convención Marco sobre Cambio Climático de las Naciones Unidas (CMCC) y su Protocolo de Kyoto, en esfuerzo por su mitigación (IPCC, 2007).

Los cambios en las concentraciones de los gases de efecto invernadero y aerosoles en la atmósfera, la variación de la cubierta terrestre y la variación de la radiación solar son factores que afectan el equilibrio del sistema climático (IPCC, 2007). Las emisiones mundiales de GEI antropógenicos han aumentado un $70 \%$ entre 1970 y el 2004 y los valores de metano $\left(\mathrm{CH}_{4}\right)$ y óxido nitroso $\left(\mathrm{N}_{2} \mathrm{O}\right)$ han aumentado notablemente desde 1750 , siendo éstos dos los principales GEI. La mayor parte del aumento de la temperatura mundial se debe a la mayor concentración de estos gases. Esto es causado, en parte, a la agricultura (Smith et al., 2007; IPCC, 2007) y en el caso del metano se debe también al uso de combustibles fósiles (IPCC, 2007). Se estima que ambos gases son responsables de un $25 \%$ del aumento del calentamiento global (Jacobson, 2005; Mosier, 1998, citado por Pereyra, 2009). En Uruguay se estima que el $90 \%$ del total de $\mathrm{CH}_{4}$ emitido proviene del sector agropecuario, del cual el $84 \%$ proviene de la fermentación ruminal del ganado, un $2 \%$ del manejo del estiércol y un $4 \%$ corresponde al generado por cultivos como el arroz (MVOTMA, 2010).

Los GEI tienen diferente capacidad de calentamiento, basado en su impacto radiativo y su duración en la atmósfera, tomando como unidad de referencia el gas dióxido de carbono $\left(\mathrm{CO}_{2}\right)$. El metano y el óxido nitroso presentan un potencial de calentamiento global 25 y 298 veces mayor respectivamente al del dióxido de carbono en un horizonte de 100 años (IPCC, 2007). El cultivo de arroz bajo riego es considerado 
una de las principales fuentes mundiales de emisión de metano $\left(\mathrm{CH}_{4}\right)$ derivadas de la actividad humana y una importante fuente de óxido nitroso $\left(\mathrm{N}_{2} \mathrm{O}\right)$.

El cultivo de arroz es el principal cultivo irrigado del Uruguay y el $90 \%$ de su producción es exportada. La producción arrocera del Uruguay comenzó a finales de 1920 (Deambrosi, 2007) y actualmente, la producción promedio, según el anuario de DIEAMGAP del 2012, es de $7850 \mathrm{~kg} / \mathrm{ha}$, para las 180.000 ha sembradas. Estos rendimientos se encuentran dentro de los mas altos del mundo, con una muy buena calidad, manteniendo una correcta relación con el ambiente (Deambrosi, 2007). El manejo del cultivo en nuestro país presenta ciertas características que lo diferencian de las producciones de otras partes del mundo. El cultivo es producido en rotación con ganadería, alternando 3-4 años de pasturas y 1-2 años de producción de arroz. Esto indica que el arroz ocupa un $25-30 \%$ del tiempo de la rotación. El arroz es sembrado mecánicamente, mediante siembra directa, sobre suelo seco entre octubre y noviembre y presenta un ciclo de cultivo por año. El cultivo se extiende 140150 días entre siembra y madurez y el suelo se mantiene inundado 55-70\% del tiempo. Un $84 \%$ del área sembrada la ocupan las variedades EI Paso 144, INIA Olimar e INIA Tacuarí (Anuario DIEA-MGAP, 2012). Dependiendo de las condiciones climáticas, se requerirán uno o dos baños para evitar el estrés hídrico en las primeras etapas del cultivo, antes de establecerse la inundación (30 días después de la emergencia del cultivo). La fertilización se realiza a la siembra con fosforo, nitrógeno y potasio y luego se fertiliza al voleo con urea al macollaje y en primordio floral. En líneas generales se aplican $40-70 \mathrm{~kg} / \mathrm{ha}$ de $\mathrm{P}_{2} \mathrm{O}_{5}$ y no más de $70 \mathrm{~kg} /$ ha de N. Una vez que el arroz es cosechado, se siembran especies forrajeras para la producción de carne en los períodos en los que el arroz no se cultiva. La rotación con pasturas ha sido el sistema predominante en Uruguay desde 1960. Con este manejo del sistema, el contenido de materia orgánica del suelo se mantiene o aumenta en relación al contenido inicial; la fertilidad y las propiedades físicas y químicas son rápida- mente mejoradas con la inclusión de pasturas en rotación con cultivos (GarcíaPréchac et al., 2004). Debido a esta rotación, el uso de pesticidas (herbicidas y fungicidas) son aplicados con muy baja frecuencia (Deambrosi, 2007; Méndez et al., 2003; Roel et al., 2007).

El gas de efecto invernadero mayormente producido en chacras de arroz inundado es el metano, contribuyendo aproximadamente un $15-20 \%$ a las emisiones globales de $\mathrm{CH}_{4}$ (Jacobson, 2005; Hadi et al., 2010). Los suelos inundados generan condiciones de anaerobiosis, favoreciendo la degradación de la materia orgánica que produce metano como producto final (Conrad, 2002). La producción de metano es influenciada por numerosos procesos que ocurren en el suelo, asi como las prácticas de manejo comúnmente utilizadas del agua, fertilización y rastrojo (Cai et al., 1997; Yan et al., 2005; Linquist et al., 2012). Su emisión es el resultado de una serie de procesos complejos, que involucra la interacción plantasmicroorganismos y su liberación hacia la atmósfera está determinada por las tasas de metanogénesis y de oxidación de metano (Mishra et al., 1997).

Por otro lado, la agricultura es la fuente principal de las emisiones de $\mathrm{N}_{2} \mathrm{O}$. Éste es producido a partir de procesos que se dan en el suelo, como la nitrificación y desnitrificación microbiana (Vibol y Towprayoon, 2010). Por otra parte, las emisiones de $\mathrm{N}_{2} \mathrm{O}$ son despreciables en cultivos de arroz bajo inundación continua (Denmead et al., 1979; Freney et al., 1981; Smith et al., 1982; Zou et al., 2005).

El agua para el riego del arroz en Uruguay proviene en un $40 \%$ de cauces naturales y en un $60 \%$ de agua represada. El $45 \%$ del agua total utilizada es propia de los productore y un 55\% es comprada (MGAP-DIEA, 2012). La precipitación promedio anual (para los últimos 33 años en la Unidad Experimental «Paso de la Laguna» de INIA Treinta y Tres) es de $1375 \mathrm{~mm}$ y aproximadamente el 50\% ocurre durante el ciclo del cultivo.

El manejo del agua es una herramienta muy importante tanto para lograr altos rendimientos, como para mitigar emisiones de 
metano. Numerosos trabajos muestran que alteraciones en el manejo del agua, como el riego intermitente o el drenaje en la mitad del ciclo del cultivo, son opciones efectivas para la mitigación de metano en el cultivo de arroz (Yagi et al., 1996; Minamikawa y Sakai, 2006; Tyagi et al., 2010; Hadi et al., 2010; Itoh et al., 2011; Jain et al., 2013). Sin embargo, la alternancia de los ciclos aeróbicos y anaeróbicos pueden estimular las emisiones de óxido nitroso y por lo tanto es necesario una compensación de emisiones que minimice la liberación de ambos gases (Zhou et al., 2005; Itoh et al., 2011).

El óxido nitroso es producido en el suelo mediante procesos bioquímicos de nitrificación y desnitrificación, influenciados por el contenido de agua en el suelo. La alternancia de suelo húmedo y seco que ocurre al drenar el suelo crea un ambiente favorable para estos dos procesos y puede llevar a mayores emisiones de óxido nitroso (Zou et al., 2007). Asimismo, sistemas que utilizan estas prácticas de drenaje son importantes para la conservación del agua y el aumento del rendimiento del cultivo (Xu et al., 2007).

A nivel internacional varios autores afirman que el manejo del agua es uno de los principales factores que afecta directamente las emisiones de $\mathrm{CH}_{4}$ y $\mathrm{N}_{2} \mathrm{O}$ en el cultivo de arroz. Estos sugieren modificar las técnicas de gestión del agua como una opción viable para mitigar las emisiones de $\mathrm{CH}_{4}$, manejando las condiciones de reducción en el cultivo. Se ha demostrado que las emisiones de $\mathrm{CH}_{4}$ son mayores en cultivos con inundación continua respecto a un cultivo manejado con riego intermitente, promoviendo a este último sistema como una estrategia potencialmente eficaz para mitigar las emisiones (Sass et al., 1992; Chen et al., 1992; Cai et al., 1994 citados por Itoh et al., 2011; Yagi et al., 1996; Minamikawa y Sakai, 2006; Shiratori et al., 2007, Towprayoon et al., 2005).

\section{Objetivos del trabajo}

La mayor parte del arroz del mundo es producido bajo condiciones de anaerobiosis continua, por lo que existen pocos trabajos sobre las emisiones de metano y óxido nitroso en sistemas similares a las condiciones de producción del Uruguay, donde hay en promedio al menos 30 días de condiciones aerobias desde la emergencia del cultivo.

Poco se conoce por lo tanto sobre los efectos integrados de la emisión de los GEI, consumo de agua y productividad en sistemas de arroz sembrados en suelos secos e inundados posteriormente.

Existe poca información nacional acerca de los niveles de emisión de GEI en el cultivo de arroz. Las primeras determinaciones fueron realizadas en el marco del Proyecto «Emisiones de metano y óxido nitroso en la rotación arroz-pastura en el este Uruguayo», financiado por el Fondo de Promoción de Tecnología Agropecuaria (FPTA) de INIA (Irisarri et al., 2010). En este trabajo se estimó una emisión total del cultivo de arroz de entre 129 y 482 kg/ha/año de $\mathrm{C}-\mathrm{CH}_{4}$ y se constató que el manejo del agua determinó, en gran medida, la dinámica de las emisiones de $\mathrm{CH}_{4}$ y $\mathrm{N}_{2} \mathrm{O}$. Por otro lado, la fertilización nitrogenada y la presencia de la cobertura invernal (raigrás) influyó positivamente en la emisión de dichos gases (Pereyra, 2009).

El presente estudio se enmarca dentro los objetivos centrales del sector arrocero Uruguayo de identificar estrategias objetivas que permitan seguir avanzando en la intensificación sustentable del arroz en Uruguay, combinando aspectos de productividad del cultivo, uso del agua y emisiones de GEI.

Los objetivos del presente estudio fueron evaluar las emisiones de $\mathrm{CH}_{4}$ y $\mathrm{N}_{2} \mathrm{O}$, el consumo de agua y la productividad del arroz bajo dos sistemas de riego contrastantes: el más comúnmente usado en Uruguay, IC30, en donde se establece la inundación continua a los 30 días de emergencia del cultivo, y el RR, con riego restringido, en donde se alternan períodos de suelo húmedo y seco hasta el estadio de primordio floral en la planta, estableciéndose luego la inundación continua.

La hipótesis de trabajo es que el cultivo de arroz bajo un sistema de riego más restringido al comúnmente utilizado permitiría disminuir las emisiones de $\mathrm{CH}_{4}$ aunque podría aumentar las emisiones de $\mathrm{N}_{2} \mathrm{O}$. 


\section{MATERIALES Y MÉTODOS}

Los experimentos se llevaron a cabo en la Unidad Experimental «Paso de la Lagu-

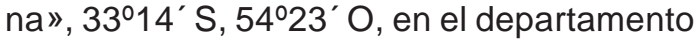
de Treinta y Tres, Uruguay, durante 3 zafras de cultivo. Zafra 1: 2010/2011, Zafra 2: 2011/ 2012, Zafra 3: 2012/2013.

El diseño del ensayo fue en bloques completos al azar, con dos tratamientos de riego $y$ tres repeticiones, evaluadas en tres zafras de cultivo. Se utilizaron parcelas de $66 \mathrm{~m}^{2}$, cada una contaba con dos campanas para medición de gases y con entrada y salida de agua de forma independiente, para permitir el manejo independiente del riego en cada una de ellas y las mediciones de agua correspondientes.
Los ensayos se instalaron sobre Brunosoles sub-eutrico lúvicos, calificados como Argiudoll según la taxonomía del USDA. Las propiedades de los suelos para las tres zafras se presentan en el Cuadro 1.

Los suelos sobre los cuales se realizaron los ensayos son de textura franca, se determinaron los porcentajes de arena, limo y arcilla (Cuadro 2).

Los ensayos fueron sembrados mediante siembra directa con la variedad de arroz (Oryza sativa) El Paso 144, cultivar con mayor porcentaje de área sembrada en el Uruguay. El cultivo se fertilizó a la siembra, al macollaje y en primordio floral (Cuadro 3 y Cuadros 15, 16 y 17 en anexos).
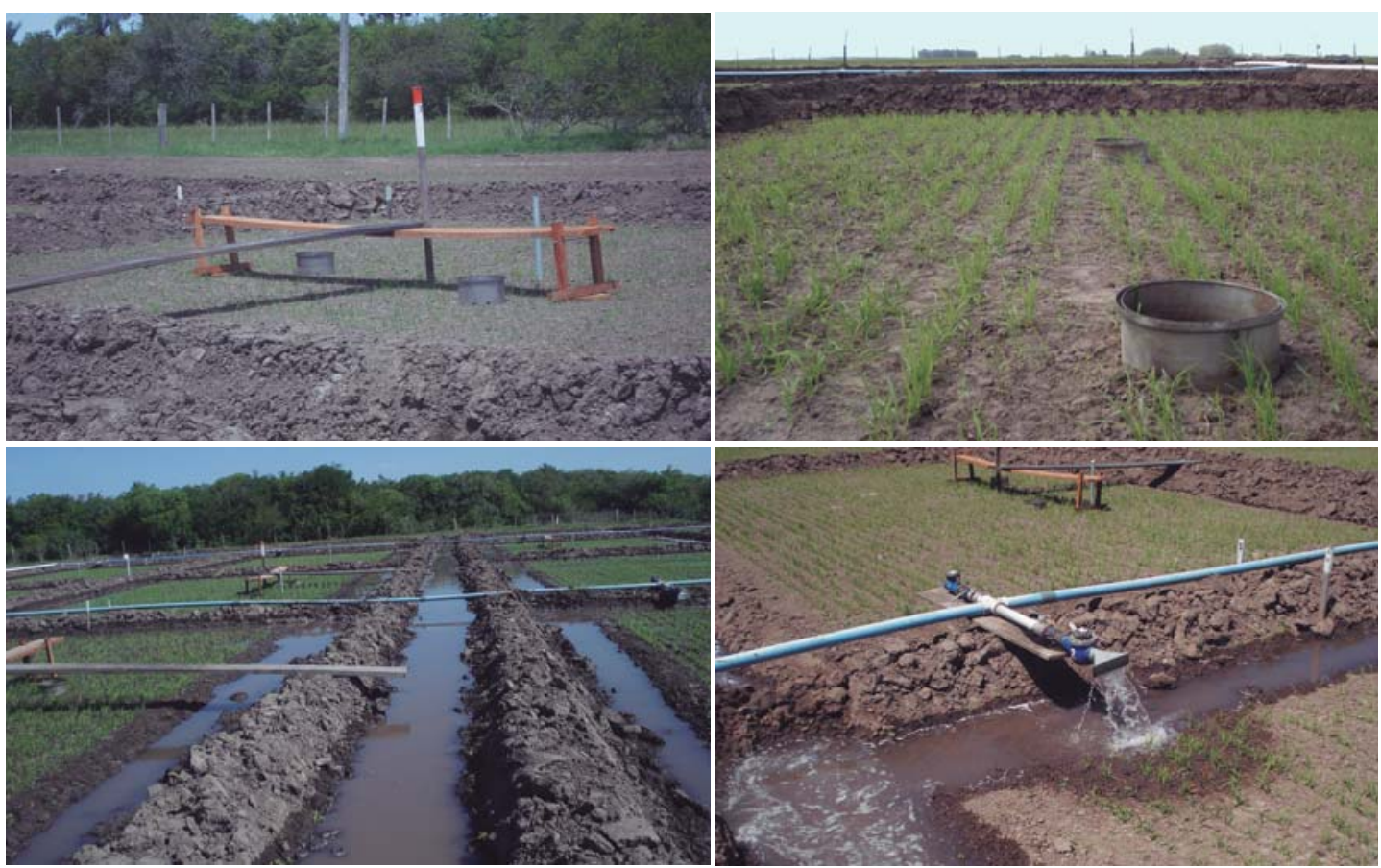

Cuadro1. Análisis de suelo para las tres zafras.

\begin{tabular}{|l|c|c|c|}
\hline Parámetro del Suelo & Zafra 1 & Zafra 2 & Zafra 3 \\
\hline $\mathrm{pH}$ (agua) & 6 & 5,5 & 6,3 \\
Materia orgánica (\%) & 2,2 & 1,9 & 2,29 \\
Fósforo - Bray I (ppm) & 5 & 5 & 2,2 \\
Fósforo - Ácido cítrico (ppm) & 4 & 5 & 11,8 \\
Potasio intercambiable (meq.K/100g) & 0,11 & 0,18 & 0,16 \\
\hline
\end{tabular}


Cuadro 2. Textura del suelo.

\begin{tabular}{|l|c|c|c|}
\hline Zafra & \% Arena & \% Limo & \% Arcilla \\
\hline 2010/2011 & 25 & 48 & 27 \\
$2011 / 2012$ y 2012/2013 & 33 & 38 & 29 \\
\hline
\end{tabular}

El cultivo de arroz fue sembrado con $150 \mathrm{~kg} / \mathrm{ha}$ de semillas. La temperatura media en torno a floración fue de $23^{\circ} \mathrm{C}$ en las tres zafras estudiadas. La temperatura media diaria y las precipitaciones para las tres zafras se muestran en las Figuras $2 a$ y $2 b$.

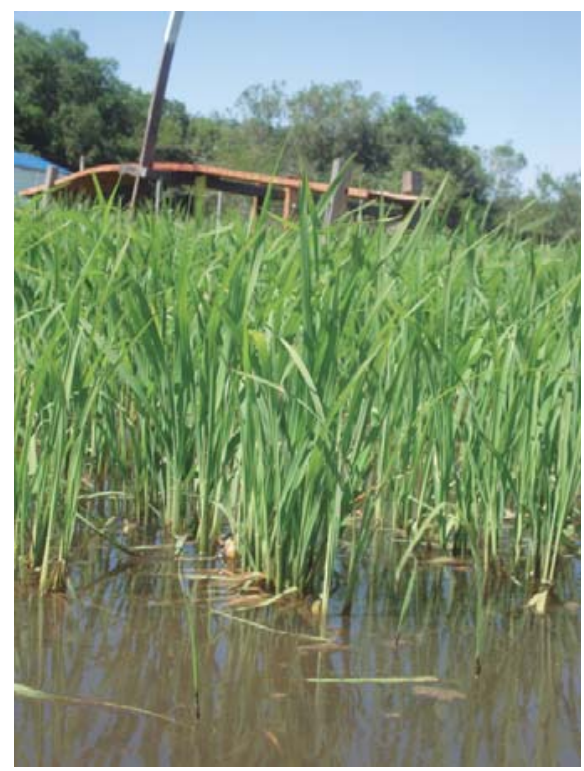

\section{Medición del agua de riego y parámetros del cultivo}

Se evaluaron dos sistemas de riego: el manejo tradicional que consistió en el establecimiento de la inundación a los 30 días después de la emergencia (IC30) en comparación con un riego restringido con déficit controlado que permitía el secado y mojado

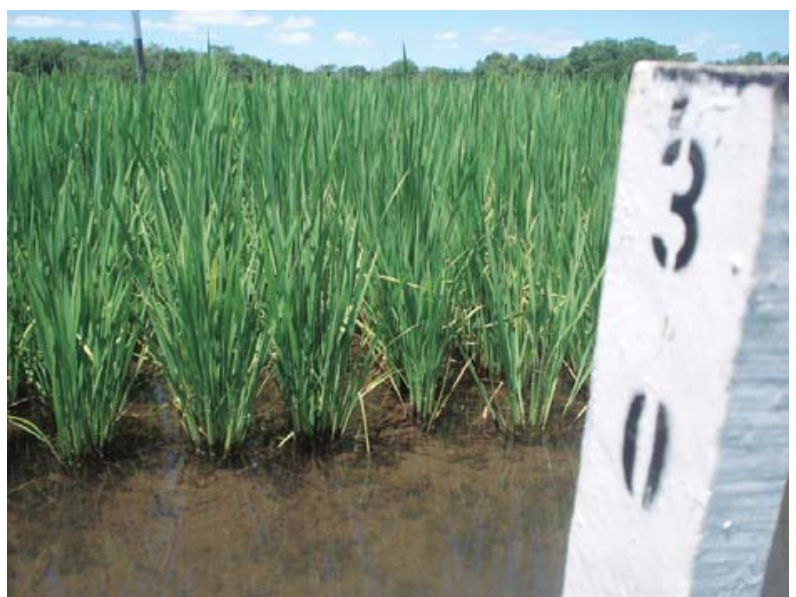

Cuadro 3. Calendario agronómico para las tres zafras.

\begin{tabular}{|c|c|c|c|c|c|c|}
\hline \multicolumn{2}{|l|}{ Zafra 1} & Zafra 2 & \multicolumn{3}{|c|}{ Zafra 3} & \multirow{2}{*}{ Práctica agronómica } \\
\hline Fecha & DDE* & Fecha & DDE* & Fecha & DDE* & \\
\hline 8/10/2010 & -33 & $22 / 10 / 2011$ & -18 & 19/10/2012 & -15 & $\begin{array}{l}\text { Siembra y fertilización basal }(16 \mathrm{~kg} / \\
\left.\text { ha N, } 66 \mathrm{~kg} / \mathrm{haP}_{2} \mathrm{O}_{5}, 18 \mathrm{~kg} / \mathrm{haK}_{2} \mathrm{O}\right) \text {. } \\
\text { Variedad: El Paso } 144\end{array}$ \\
\hline 10/11/2010 & 0 & 09/11/2011 & 0 & 03/11/2012 & 0 & Emergencia del cultivo \\
\hline 30/10/2010 & -11 & 30/10/2011 & -10 & $12 / 11 / 2011$ & 9 & \multirow{2}{*}{ Aplicación de herbicida } \\
\hline 19/11/2010 & 9 & 22/11/2011 & 13 & 29/11/2012 & 26 & \\
\hline 13/12/2010 & 33 & 09/12/2011 & 30 & 03/12/2012 & 30 & $\begin{array}{l}\text { Fertilización a Macollaje (60kg/ha } \\
\text { urea) }\end{array}$ \\
\hline IC30:03/01/2011 & 54 & IC30:06/01/2012 & 58 & IC30:28/12/2012 & 55 & \multirow{2}{*}{$\begin{array}{l}\text { Fertilización a primordio floral } \\
(50 \mathrm{~kg} / \mathrm{ha} \text { urea })^{\star \star}\end{array}$} \\
\hline RR:13/01/2011 & 64 & RR:20/01/2012 & 72 & RR:07/01/2013 & 65 & \\
\hline IC30:13/12/2010 & 33 & IC30:09/12/2011 & 30 & IC30:03/12/2012 & 30 & \multirow{2}{*}{ Inundación } \\
\hline RR:13/01/2011 & 64 & RR: 20/01/2012 & 72 & RR:07/01/2013 & 65 & \\
\hline
\end{tabular}

* Días después de emergencia.

** Aplicación de Urea con suelo seco: previo a la inundación en el tratamiento IC30 y previo al primer riego en el tratamiento RR. 


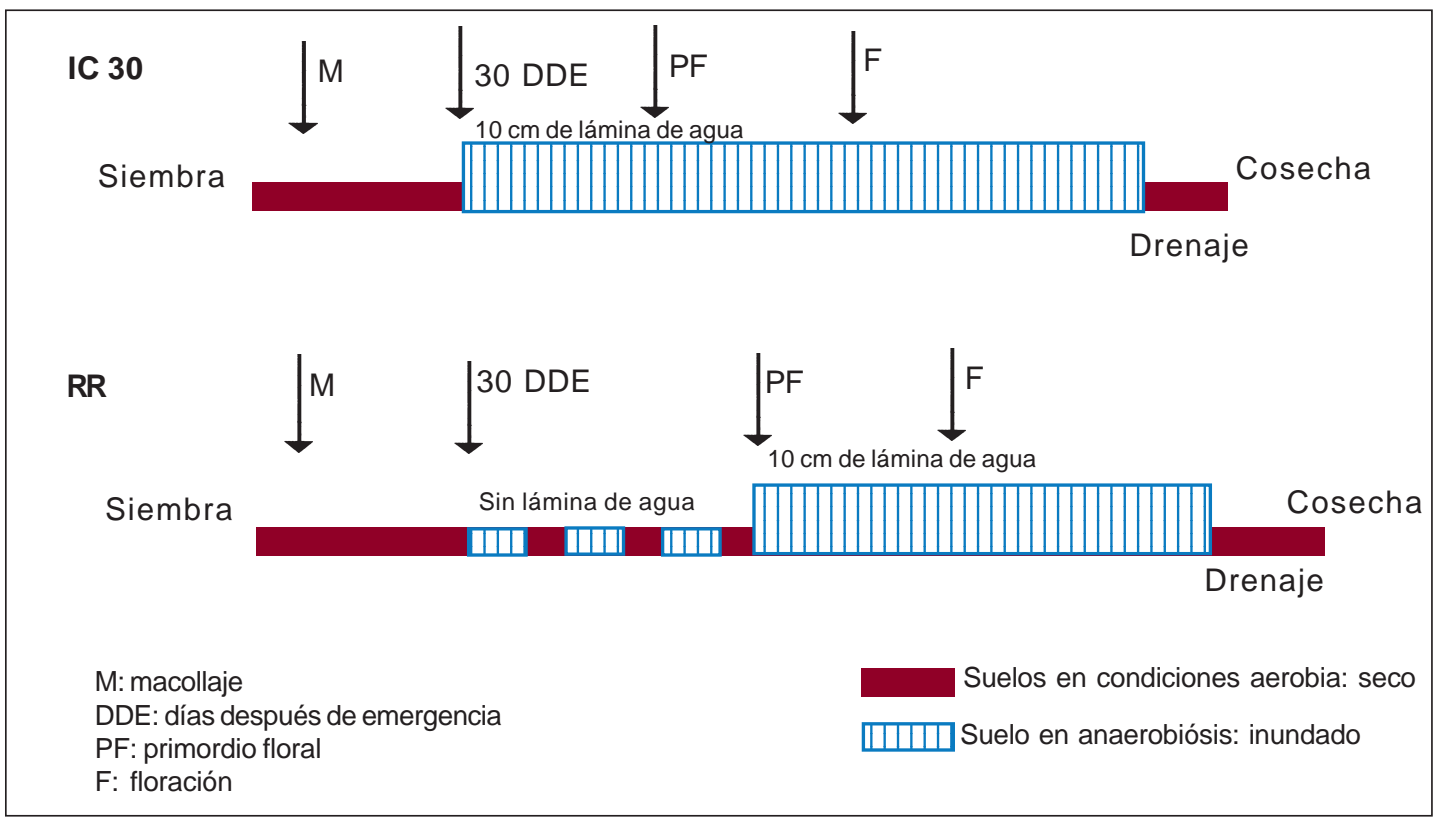

Figura 1. Representación del ciclo del cultivo para los tratamientos de inundación continua (IC30) y riego con déficit controlado (RR).

del suelo (RR). Los tratamientos se aprecian de forma esquemática en la Figura 1.

Para el tratamiento IC30, la inundación permanente se estableció a los 30 días después de la emergencia (DDE) y continuó el riego hasta 15 días posteriores al 50\% de floración (F). En el caso del RR, el tratamiento se inició en este mismo momento (a los 30 DDE) y se llevó a cabo hasta el inicio de la fase reproductiva (diferenciación del primordio floral, PF), momento a partir del cual se estableció la inundación continua, siguiendo el mismo manejo que el tratamiento IC30.

El criterio de suministro de agua durante la fase vegetativa para el tratamiento RR con-

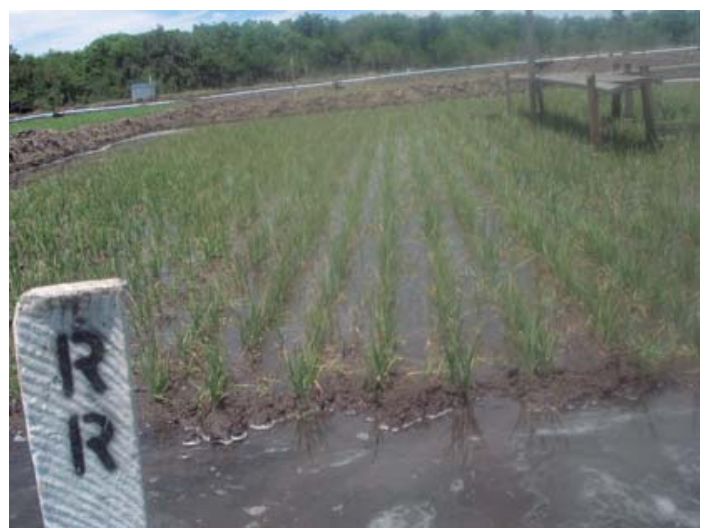

sistió en la alternancia de suelo seco con suelo saturado. El tratamiento se inició en condiciones de suelo saturado y cuando se consumió (evapotranspiró) el 50\% del agua disponible en el suelo, se suministró agua de manera de que este quede nuevamente saturado, alternando de esta manera períodos de suelo húmedo y seco (ver variabilidad de humedad del suelo en Figura 7 , anexos). Cuando el cultivo alcanzó la fase de primordio floral se estableció la inundación continua, al igual que el tratamiento IC 30, con una lámina de agua de $10 \mathrm{~cm}$, discontinuando los riegos 15 días después del haber alcanzado el $50 \%$ de floración.

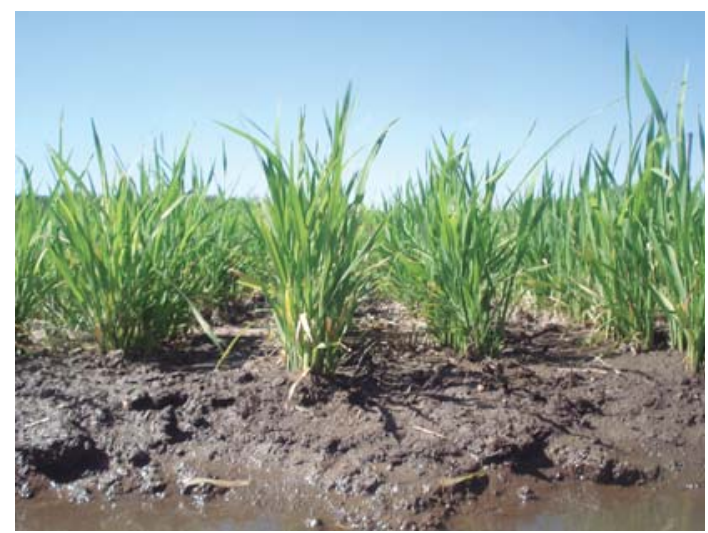




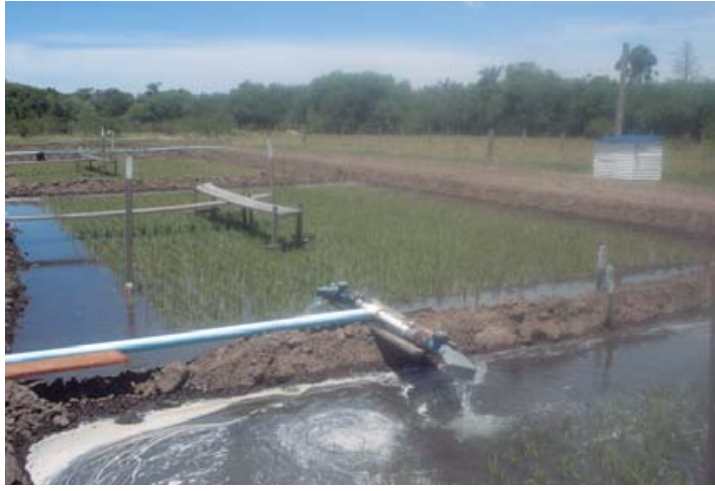

Las aplicaciones de agua para el tratamiento RR fue basado en la evapotranspiración diaria del cultivo (ETc), según la ecuación de Penman-Monteith (FAO N56). El riego se realió cuando la ETC acumulada fue igual al 50\% del agua disponible en el suelo (25 $\mathrm{mm}$ para un perfil de $30 \mathrm{~cm}$ del suelo analizado).

El agua de riego que se proporcionó fue medida con un caudalímetro, ARAD WMR 50 , instalado en la entrada de cada parcela. El agua de riego aplicada en cada parcela se encuentra detallada para cada zafra en las tablas 19, 20 y 21 en anexos. El agua de lluvia fue medida con un pluviómetro instalado en la estación climática a 100 m del ensayo. El agua total para cada parcela corresponde a la suma del agua de riego más el agua de precipitaciones. El contenido de agua en el suelo en las primeras etapas del cultivo se registró diariamente, cada 1 hora, mediante sensores FDR, EC 5, de Decagon, ubicados a $10 \mathrm{~cm}$ de profundidad.

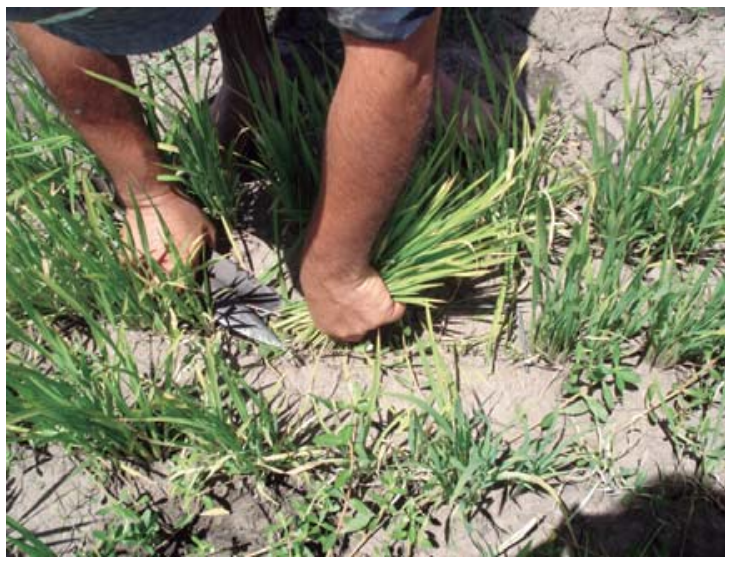

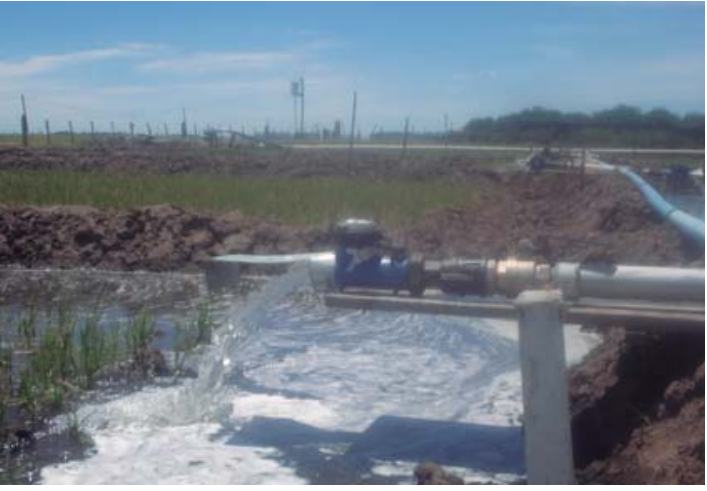

La materia seca del cultivo se determinó mediante dos cortes de $50 \mathrm{~cm}$ por parcela, llevados a estufa, con una frecuencia de 15 días, al mismo tiempo que se tomaban cuatro lecturas de altura de planta por parcela.

El rendimiento se determinó cosechando un área de $6,12 \mathrm{~m}^{2}$ (12 hileras $\times 3 \mathrm{~m}$ ), en el centro de cada parcela. El rendimiento reportado refiere al peso de los granos de arroz cosechados corregidos a $14 \%$ de humedad en grano.

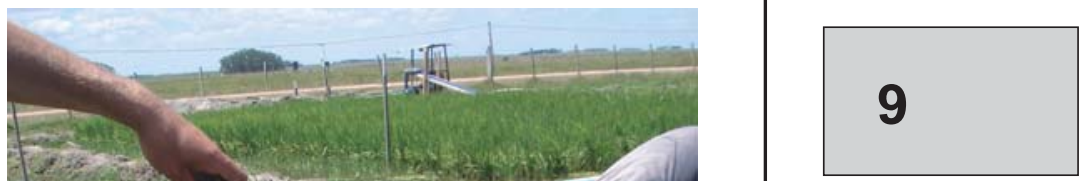




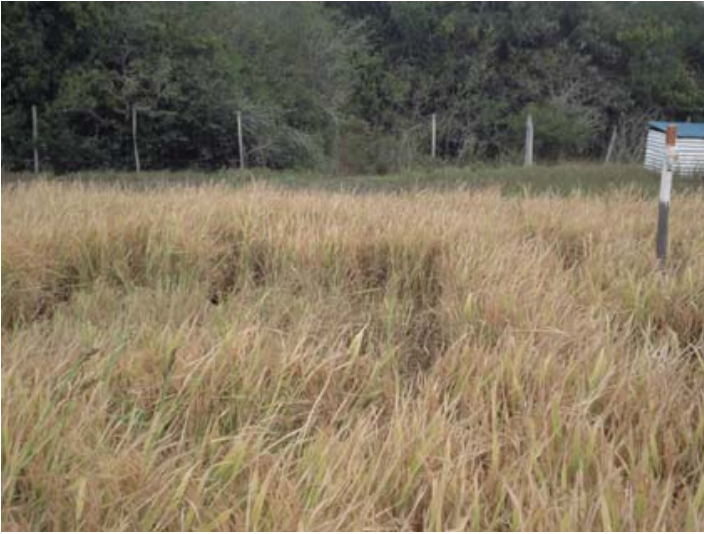

El potencial de oxidación y reducción (redox) fue medida en la Zafra 3, 2012/2013, usando un electrodo manual de vidrio, Horiba $\mathrm{D}-52$, de rango -1999 hasta $1999 \mathrm{mV}$ y de 0 a $100^{\circ} \mathrm{C}$, con una resolución de $0,1^{\circ} \mathrm{C}$. Se tomaron medidas instantáneas semanales para ambos tratamientos de la entre-fila del cultivo a una profundidad de $10 \mathrm{~cm}$, con cinco réplicas por parcela.

\section{Muestreo y cuantificación del GEI}

Para cuantificar la magnitud del flujo de $\mathrm{CH}_{4}$ y $\mathrm{N}_{2} \mathrm{O}$ emitidos, se utilizó el «método de cámaras cerradas» (IAEA, 1992), según la técnica descripta por Lindau et al., 1991. El método utiliza cilindros de acrílico transparentes (de $60 \mathrm{~cm}$ de altura), diseñados en el marco del proyecto FPTA $\mathrm{N}^{\circ} 238$. Dichas cámaras permiten permiten incluir la planta de arroz hasta su máximo desarrollo, considerando que el transporte de $\mathrm{CH}_{4}$ hacia la atmósfera se da mayoritariamente a través de la planta, a pesar de producirse en el suelo (Nouchi y col., 1990; Irisarri et al., 2010). Al momento de tomar las muestras de aire, dichas cámaras eran colocadas sobre una base de acero inoxidable. Dichas bases tenian $20 \mathrm{~cm}$ de altura y $40 \mathrm{~cm}$ de diámetro, y fueron enterradas $10 \mathrm{~cm}$ en el suelo, las cuales permanecieron en el lugar durante todo el transcurso del experimento. La unión de ambas partes se aseguró mediante un cierre de agua para evitar el escape de los gases. Cada camara contaba con un ventilador

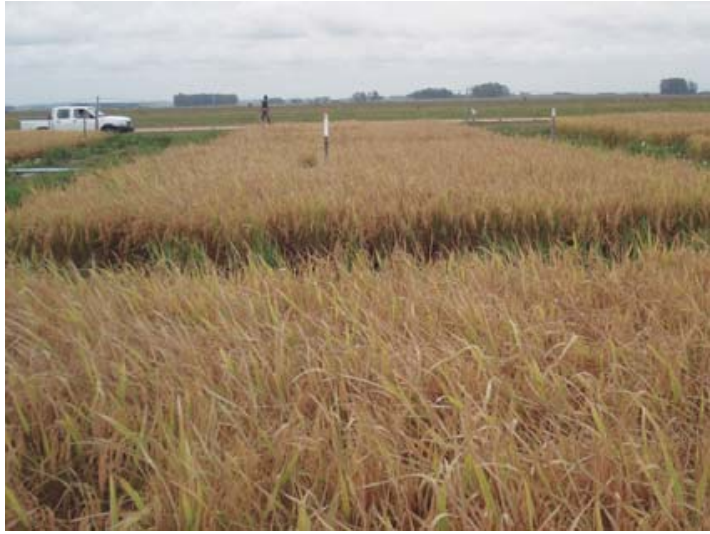

a batería, el cual se prendía 5 minutos antes de las mediciones para asegurar la homogeneidad de la atmósfera interior. Contaban también con un «tubo de ventilación» atravesando su sección superior, conectado en su extremo a un globo de goma, con el fin de mantener el equilibrio entre las presiones externa e interna de la cámara. Algunas cámaras tenían un termómetro interno para la detección y el seguimiento de la temperatura dentro de las mismas. Las muestras se extrajeron con jeringas de plástico descartables de $25 \mathrm{ml}$, según los criterios que se presentan en el Cuadro 4. Las muestras se almacenaron en tubos al vacío (vacutainers) de $10 \mathrm{ml}$ hasta su posterior análisis. Cada muestra se realizó por duplicado, como control de calidad.

Las frecuencias de toma de muestras fue cada siete días, intervalo de tiempo sugerido para obtener una aproximación a la estimación de las emisiones de metano en sistemas arroceros (Minamikawa et al., 2012). Las medidas fueron realizadas entre las 11 y 12 am de manera que fueran representativas del promedio del día (Minamikawa et al., 2012). En cada parcela se colocaron dos campanas. Para cada medición se registró la temperatura, el nivel de agua dentro de cada campana y el espacio libre dentro de la misma, para el cálculo de las tasas de emisión de los gases, mediante el aumento lineal de la concentración de los mismos durante el tiempo. Se registraron 19 plantas promedio dentro de cada una de las campanas. 
Cuadro 4. Criterios para la toma de muestras de $\mathrm{CH}_{4}$ y $\mathrm{N}_{2} \mathrm{O}$.

\begin{tabular}{|c|c|c|}
\hline & Momento de muestreo & Intervalos de medición por muestreo* \\
\hline $\mathrm{N}_{2} \mathrm{O}$ & $\begin{array}{l}\text { Desde emergencia hasta dos } \\
\text { semanas después de establecida la } \\
\text { inundación permanente (una vez por } \\
\text { semana) } \\
\text { Luego de cosecha (una medición) }\end{array}$ & $\begin{array}{l}\text { Tres medidas a intervalos de } 15 \text { minu- } \\
\left.\text { tos (tiempos } 0-15^{\prime}-30^{\prime}\right)\end{array}$ \\
\hline $\mathrm{CH}_{4}$ & $\begin{array}{l}\text { Desde emergencia hasta } 15 \text { días } \\
\text { después de cosecha (una vez por } \\
\text { semana) }\end{array}$ & $\begin{array}{l}\text { Tres medidas a intervalos de } 30 \text { minutos } \\
\text { (tiempos } 0-30^{\prime}-60^{\prime} \text { ) }\end{array}$ \\
\hline
\end{tabular}

*En el momento del muestreo se tomaron tres muestras en tubos al vacío para cada intervalo de medición.

El análisis de las concentraciones de $\mathrm{CH}_{4}$ y $\mathrm{N}_{2} \mathrm{O}$ en las muestras de aire se realizó mediante cromatografía gaseosa en el laboratorio de microbiología de la Facultad de Química. Se utilizó el cromatógrafo Chrompach CP 9001 equipado con detector FID para el análisis de metano. Para el análisis de óxido nitroso se utilizó un Shimadzu 14B con un detector ECD, como lo describen Perdomo et al. (2009). Los cromatogramas de $\mathrm{N}_{2} \mathrm{O}$ y $\mathrm{CH}_{4}$ obtenidos fueron analizados mediante el software GC Solution y el software PeakSimple, respectivamente. La tasa de emisión de ambos gases se calculó según Watanabe et al. (2000): $\mathrm{F}=\tilde{n} . \mathrm{h}(\mathrm{dC} / \mathrm{dt}$ ), donde $\mathrm{F}$ corresponde a la tasa de emisión de $\mathrm{N}-\mathrm{N}_{2} \mathrm{O} \circ \mathrm{C}-\mathrm{CH}_{4}$ en $\mathrm{g} / \mathrm{ha} / \mathrm{d}$; $\tilde{n}$ es la densidad de $\mathrm{N}-\mathrm{N}_{2} \mathrm{O} \circ \mathrm{C}-\mathrm{CH}_{4}$ corregida por la temperatura existente en el interior de la cámara de muestreo; h es la altura de la cámara desde el suelo o el nivel de agua y dC/dt es el incremento de la concentración de $\mathrm{N}_{2} \mathrm{O} 0$ $\mathrm{CH}_{4}$ dentro de la campana con el tiempo. $\mathrm{La}$ tasa de emisión obtenida para las réplicas de cada tratamiento fue promediada para determinar el valor final de emisión por tratamiento.

Las emisiones de GEI durante toda la zafra del cultivo se calcularon integrando el área debajo de la curva para cada flujo de emisión de los gases. Se ajustó un modelo cúbico para las emisiones totales de metano para la zafra y las emisiones de óxido nitroso fueron calculadas sumando todos los valores de flujo de masa en el período experimental. El flujo de masa neto de óxido nitroso entre dos fechas de medición se calculó como los valores medios de flujo de las dos fechas multiplicado por el número de días entre dichas fechas (Bowden et al., 1990).

El potencial de calentamiento global (PCG) del metano y óxido nitroso fue calcu-
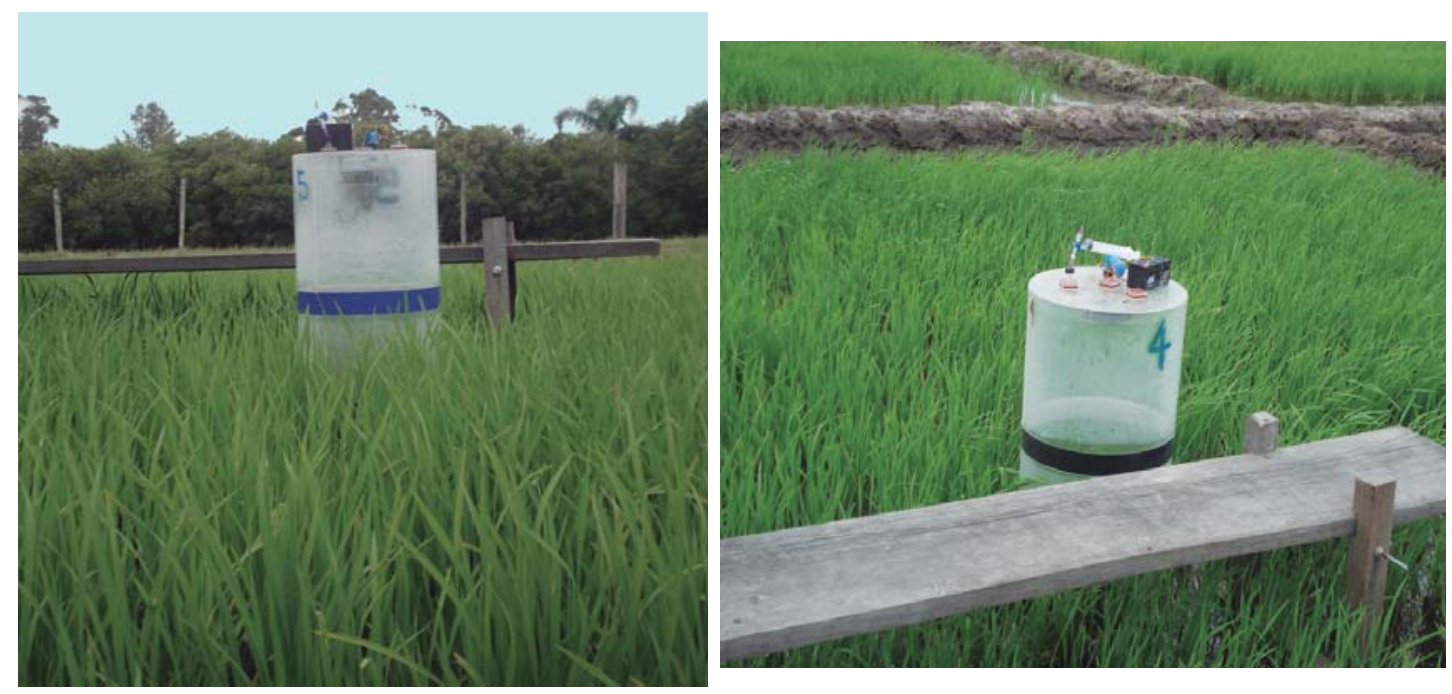
lado en unidades de $\mathrm{CO}_{2}$ equivalentes $\left(\mathrm{CO}_{2}\right.$ eq.) para un período temporal de 100 años. La fuerza Radiativa potencial, relativa al $\mathrm{CO}_{2}$ usada para el $\mathrm{N}_{2} \mathrm{O}$ fue de 298 y para el $\mathrm{CH}_{4}$ fue de 25 (IPCC, 2001, 2007). El dióxido de carbono $\left(\mathrm{CO}_{2}\right)$ no fue incluido en este análisis como contribuyente al PCG. El PCG a escala del rendimiento (PCGR) fue calculado como el PCG dividido por el rendimiento de grano/ha.

\section{Análisis estadístico}

Las diferencias encontradas en las emisiones de $\mathrm{CH}_{4}$ y $\mathrm{N}_{2} \mathrm{O}$ acumulativas, PCG, rendimiento de grano y PCG a escala del rendimiento, fueron comparadas entre los tratamientos de riego utilizando un modelo lineal mixto en SAS ${ }^{\circledR}$ versión 9.3 (SAS Institute Inc., 2004) con el procedimiento PROC MIXED. EI tratamiento de riego fue considerado un efecto fijo en el modelo, mientras que los bloques, zafra y tratamiento por zafra se incluyeron como efectos aleatorios. El nivel de significancia utilizado fue del $5 \%$.

Para metano y óxido nitroso se ajustó un modelo utilizando PROC REG en SAS para estimar parámetros de regresión. El análisis de varianza se realizó por zafra, salvo cuando se detectó significancia por las interacciones de tratamiento.

\section{RESULTADOS Y DISCUSIÓN}

Los sistemas de producción de arroz tienen características particulares, expuestas anteriormente, que los hacen distintos a los de otros cultivos agrícolas. En los sistemas arroceros el gas de mayor importancia por las cantidades producidas y emitidas es el metano y las estrategias más prometedoras para la reducción de dichas emisiones son las relacionadas al manejo del agua (Yagi, K. et al., 1996).

Según Yagi et al. (1996), es posible controlar las emisiones de metano del cultivo de arroz mediante prácticas de manejo agronómico. Las opciones que se plantean son tratamientos de riego intermitente, manejo de la materia orgánica, fertilizantes minerales y enmiendas orgánicas, cambiando la forma de laboreo, rotaciones de cultivos y la selección de variedades de arroz.

Las emisiones de óxido nitroso dependen significativamente del régimen hídrico durante la estación de crecimiento. En tratamientos de inundación continua, las emisiones de este gas pueden ser altas cuando se produce el drenaje (Zou et al., 2007). La alternancia de suelo seco y húmedo crea un ambiente favorable para la nitrificacion y desnitrificacion y por lo tanto para mayores emisiones de óxido nitroso (Zou et al., 2007).

Además de controlar las emisiones de GEI, el manejo del agua tiene repercusiones importantes en el crecimiento y la fenología del cultivo, que podrán repercutir en el rendimiento final.

\section{Caracterización climática de las zafras analizadas}

La temperatura tiene efectos sobre la emisión de GEI, no solo porque afecta a los microorganismos responsables de llevar a cabo los procesos de producción y consumo de $\mathrm{CH}_{4}$ presentes en el suelo también sino afecta la conductancia a través de la planta de arroz para el transporte del $\mathrm{CH}_{4}$ producido en el suelo (Nouchi et al., 1994; Minoda y Kimura, 1994; Yang y Chang, citados por Minamikawa et al., 2006).

En las Figuras $2 a$ y $2 b$ se presentan la temperatura media atmosférica y las precipitaciones ocurridas en el período en que se realizaron los muestreos para las tres zafras estudiadas. La temperatura media en torno a floración fue de $23^{\circ} \mathrm{C}$.

Por otro lado, en cuanto a las precipitaciones, si bien es importante la cantidad total de agua proporcionada por las lluvias, su distribución es de suma relevancia en la definición de los subsecuentes riegos. Las lluvias desde siembra a cosecha para las tres zafras (Cuadro 5) se distribuyeron en forma diferente, según las características de cada año. En la Zafra 3, debido a las precipitaciones y su distribución en el tiempo, se requirieron menores cantidades de agua de riego durante el período entre siembra e inundación permanente. De manera opuesta, la Zafra 1 presentó menos días de lluvia en di- 


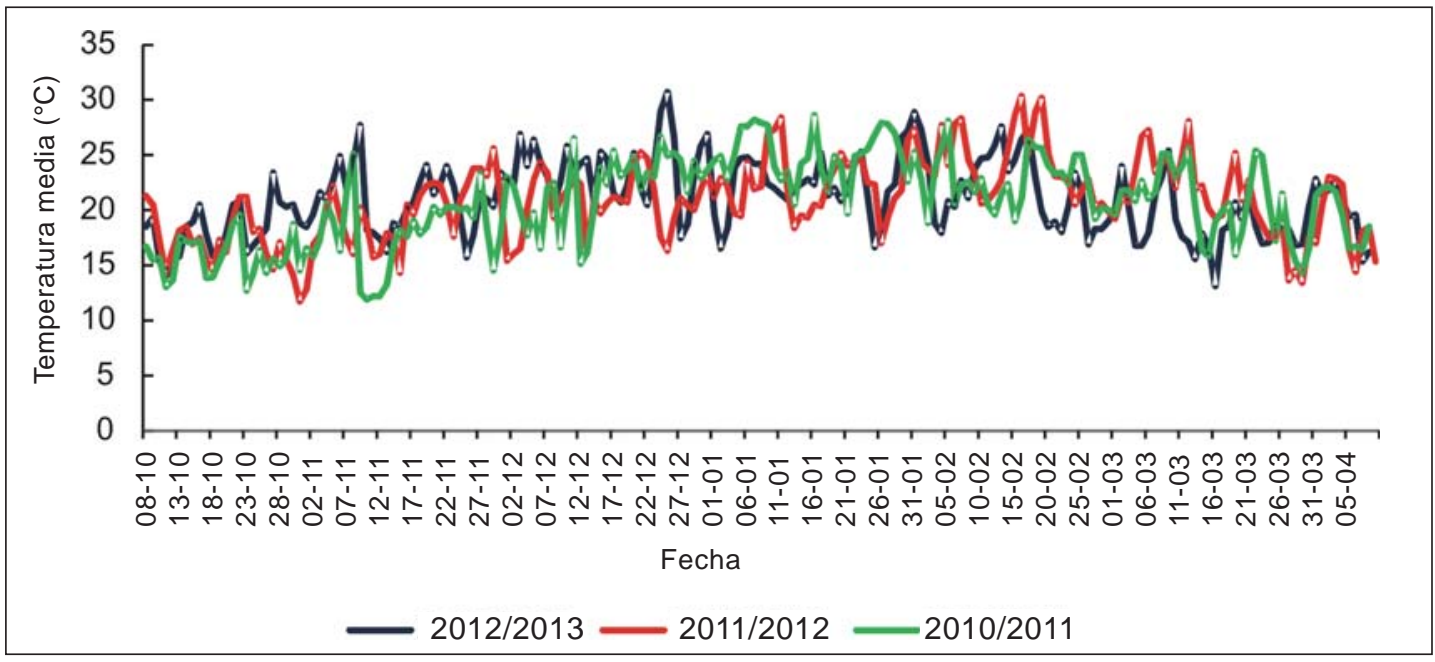

Figura 2a. Evolución de la temperatura media diaria para las tres zafras estudiadas.

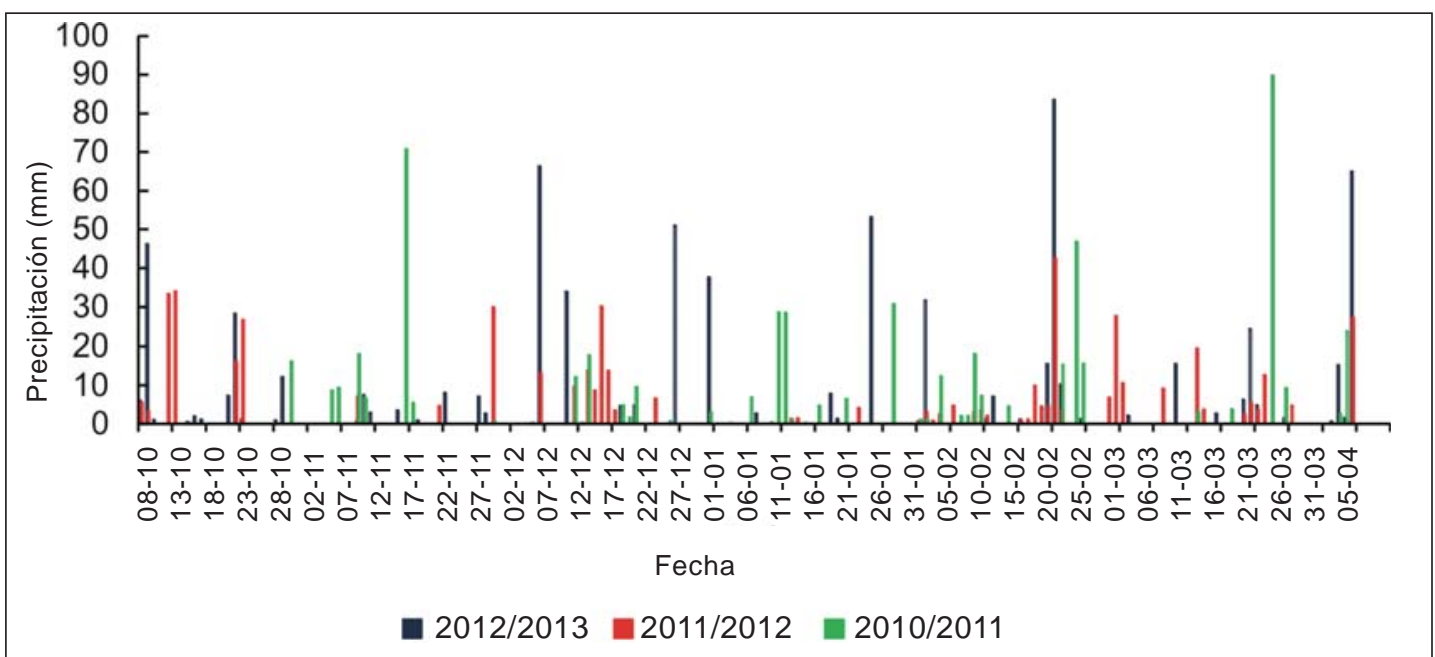

Figura 2b. Precipitación diaria para las tres zafras estudiadas.

cho período. En la Zafra 2 las lluvias se distribuyeron de forma irregular, luego de la siembra no ocurrieron precipitaciones, pero más adelante en el tiempo se presentaron períodos lluviosos (Figura 2b). El agua de riego aplicada en cada parcela se encuentra detallada para cada zafra en los Cuadros 18 , 19 y 20 en anexos.

Cuadro 5. Precipitación ( $\mathrm{mm})$ desde siembra a cosecha para las tres zafras.

\begin{tabular}{|c|ccc|}
\hline \multirow{2}{*}{ Tratamiento } & \multicolumn{3}{|c|}{ Zafra } \\
\cline { 2 - 4 } & $\mathbf{1}$ & $\mathbf{2}$ & $\mathbf{3}$ \\
\hline IC30 & 521,5 & 380,5 & 552,3 \\
\hline RR & 547,6 & 407,6 & 633,8 \\
\hline
\end{tabular}

En los cuadros 21 a 26 en anexos se procedió a comparar las horas de sol y las temperaturas medias y mínimas en el período 20 días previos y 20 días posteriores a floración, de cada tratamiento y sus promedios históricos. En términos generales, para el promedio de las tres zafras analizadas, se puede decir que un manejo del agua como el del tratamiento RR presenta 0,3 horas menos de sol en relación a un manejo tradicional.

En cuanto a las temperaturas en torno a floración se encontró, en promedio para las tres zafras estudiadas, que el tratamiento RR presentaba temperaturas mínimas diarias $0,6^{\circ} \mathrm{C}$ por encima que el tratamiento IC30 y 
una temperatura media diaria $0,2^{\circ} \mathrm{C}$ superior (Cuadros 25, 26 y 27 en anexos).

\section{Evolución del crecimiento y fenología del cultivo}

Fue clara la evidencia de los tratamientos de riego evaluados sobre la fenología del cultivo, como se observa en los Cuadros 6 y 7. El tratamiento RR presentó un ciclo de cultivo más largo que el inundado a los 30 DDE. El tratamiento IC30 se inundó antes que RR y presentó menor cantidad de días de riego que el $\mathrm{RR}$, ya que su ciclo es más corto, como se aprecia claramente en el Cuadro 7.

El arroz puede ser afectado cuando el contenido de agua en el suelo es inferior al punto de saturación, como es el caso del tratamiento RR, dependiendo del momento y la severidad de la sequía (Bouman y Tuong, 2001).

Al igual que en trabajos realizados por Bouman y Tuong (2001), en este trabajo se

Cuadro 6. Estadios fisiológicos del cultivo de arroz para las tres zafras.

\begin{tabular}{|c|c|c|c|c|}
\hline & Primordio Floral & Floración* & Fin del riego & Cosecha \\
\hline \multicolumn{5}{|c|}{ Tratamiento de Inundación Continua - IC30 } \\
\hline Zafra 1 & 3 enero & 12 febrero & 27 febrero & 30 marzo \\
\hline Zafra 2 & 6 enero & 14 febrero & 29 febrero & 30 marzo \\
\hline Zafra 3 & 28 diciembre & 9 febrero & 24 febrero & 1 abril \\
\hline \multicolumn{5}{|c|}{ Tratamiento de Riego Restringido - RR } \\
\hline Zafra 1 & 15 enero & 15 febrero & 1 marzo & 5 abril \\
\hline Zafra 2 & 20 enero & 20 febrero & 6 marzo & 9 abril \\
\hline Zafra 3 & 7 enero & 11 febrero & 26 febrero & 5 abril \\
\hline
\end{tabular}

*50\% de floración.

Cuadro 7. Efectos de los tratamientos de riego sobre la fenología y días de riego del cultivo para las tres zafras.

\begin{tabular}{|c|c|c|c|}
\hline Tratamiento & $\begin{array}{l}\text { Días de ciclo } \\
\text { del cultivo* }\end{array}$ & $\begin{array}{l}\text { Días hasta } \\
\text { Floración** }\end{array}$ & $\begin{array}{c}\text { Días de tratamiento } \\
\text { de riego*** }\end{array}$ \\
\hline \multicolumn{4}{|c|}{ Tratamiento de Inundación Continua - IC30 } \\
\hline Zafra 1 & 140 & 93 & 77 \\
\hline Zafra 2 & 142 & 97 & 83 \\
\hline Zafra 3 & 149 & 98 & 83 \\
\hline Promedio & 144 & 96 & 81 \\
\hline \multicolumn{4}{|c|}{ Tratamiento de Riego Restringido - RR } \\
\hline Zafra 1 & 146 & 95 & 79 \\
\hline Zafra 2 & 152 & 103 & 88 \\
\hline Zafra 3 & 153 & 100 & 85 \\
\hline Promedio & 150 & 99 & 84 \\
\hline
\end{tabular}

*Desde emergencia a cosecha

**Desde emergencia hasta $50 \%$ de floración.

***Desde el inicio de tratamiento (a inundación en el caso de IC30 y a los 30 DDE para RR), hasta 15 días después del $50 \%$ de floración. 
evidencian también mecanismos del arroz frente a contenidos de agua en el suelo menores a saturación, como lo son, entre otros, la reducción en la altura de planta, atraso de la floración y cambios en la partición de asimilados o almacenamiento de los mismos en raíces y tallos para liberarse posteriormente, que podrían afectar la biomasa en determinados momentos del ciclo del cultivo.

El manejo del agua repercutió significativamente en la evolución de la altura y la biomasa del cultivo como se observa en los Cuadros $8 \mathrm{a}$, b y c, y $9 \mathrm{a}$, b y c. En términos generales se observaron grandes diferencias en altura de planta en las etapas iniciales del cultivo, que se atenuaron hacia el fin del ciclo, sin embargo nunca llegaron a ser plantas de igual porte. En lo que respecta a biomasa, se encontraron grandes diferencias entre ambos tratamientos a lo largo del ciclo, presentando a cosecha una diferencia de $3607 \mathrm{~kg} / \mathrm{ha}$ de materia seca a favor del tratamiento IC30.

\section{Patrones estacionales de emisión de metano y óxido nitroso}

Los flujos de $\mathrm{CH}_{4}$ y $\mathrm{N}_{2} \mathrm{O}$ en los arrozales presentan patrones diurnos distintivos: las tasas de emisión suelen aumentar rápidamente después del amanecer, se da un pico de emisión y luego cae rápidamente, estabilizándose por la noche (Schutz et al., 1989; Yagi y Minami, 1993, citados por Neue, 1997). Es importante resaltar que en este estudio se corrigieron los valores de emisiones considerando las temperaturas medias del día para tener el dato representativo de emisión media diaria.

Para todos los años y manejos del agua de riego se encontró un patrón de emisión similar como se observa en la Figura 3a. Las emisiones de metano aumentaron gradualmente con el transcurso de los días luego de la inundación y llegaron a un pico de máxima emisión en torno a floración. En las

Cuadro 8a. Evolución de la altura del cultivo (cm) para la Zafra 1.

\begin{tabular}{|l|c|c|c|c|c|c|c|c|}
\hline & 9 DDE & 49 DDE & 54 DDE & 58 DDE & 70 DDE & 90 DDE & 103 DDE & 125 DDE \\
\hline IC30 & 16 & $39 \mathrm{a}$ & $41 \mathrm{a}$ & $52 \mathrm{a}$ & $66 \mathrm{a}$ & 79 & 80 & $88 \mathrm{a}$ \\
\hline RR & 16 & $30 \mathrm{~b}$ & $34 \mathrm{~b}$ & $35 \mathrm{~b}$ & $48 \mathrm{~b}$ & 73 & 79 & $82 \mathrm{~b}$ \\
\hline Promedio & $\mathbf{1 6}$ & $\mathbf{3 4}$ & $\mathbf{3 7}$ & $\mathbf{4 4}$ & $\mathbf{5 7}$ & $\mathbf{7 6}$ & $\mathbf{8 0}$ & $\mathbf{8 5}$ \\
\hline
\end{tabular}

Letras diferentes en una misma columna son estadísticamente diferentes, $p<0,05$.

DDE: días después de emergencia.

Cuadro 8b. Evolución de la altura del cultivo (cm) para la Zafra 2.

\begin{tabular}{|l|c|c|c|c|c|c|c|c|}
\hline & 28 DDE & 49 DDE & 56 DDE & 64 DDE & 78 DDE & 92 DDE & 100 DDE & 126 DDE \\
\hline IC30 & 16 & 40 & $40 \mathrm{a}$ & $48 \mathrm{a}$ & $66 \mathrm{a}$ & $79 \mathrm{a}$ & $84 \mathrm{a}$ & 87 \\
\hline RR & 15 & 30 & $31 \mathrm{~b}$ & $31 \mathrm{~b}$ & $37 \mathrm{~b}$ & $66 \mathrm{~b}$ & $68 \mathrm{~b}$ & 77 \\
\hline Promedio & $\mathbf{1 5}$ & $\mathbf{3 5}$ & $\mathbf{3 6}$ & $\mathbf{3 9}$ & $\mathbf{5 2}$ & $\mathbf{7 2}$ & $\mathbf{7 6}$ & $\mathbf{8 2}$ \\
\hline
\end{tabular}

Letras diferentes en una misma columna son estadísticamente diferentes, $p<0,05$.

DDE: días después de emergencia.

Cuadro 8c. Evolución de la altura del cultivo (cm) para la Zafra 3.

\begin{tabular}{|l|c|c|c|c|c|c|c|c|}
\hline & 34 DDE & 46 DDE & 55 DDE & 74 DDE & 90 DDE & 97 DDE & 111 DDE & 125 DDE \\
\hline IC30 & 17 & $40 \mathrm{a}$ & $50 \mathrm{a}$ & $75 \mathrm{a}$ & 81 & $85 \mathrm{a}$ & $90 \mathrm{a}$ & 90 \\
\hline RR & 15 & $36 \mathrm{~b}$ & $41 \mathrm{~b}$ & $59 \mathrm{~b}$ & 78 & $80 \mathrm{~b}$ & $86 \mathrm{~b}$ & 88 \\
\hline Promedio & $\mathbf{1 6}$ & $\mathbf{3 8}$ & $\mathbf{4 6}$ & $\mathbf{6 7}$ & $\mathbf{7 9}$ & $\mathbf{8 3}$ & $\mathbf{8 8}$ & $\mathbf{8 9}$ \\
\hline
\end{tabular}

Letras diferentes en una misma columna son estadísticamente diferentes, $p<0,05$.

DDE: días después de emergencia. 
Cuadro 9a. Evolución de la biomasa del cultivo (kg/ha) para la Zafra 1.

\begin{tabular}{|l|c|c|c|c|c|c|}
\hline & 29 DDE & 49 DDE & 61 DDE & 70 DDE & Floración* & Cosecha \\
\hline IC30 & 167 & 1780 & 3558 & $6052 \mathrm{a}$ & $14405 \mathrm{a}$ & 23114 \\
\hline RR & 245 & 1621 & 2658 & $3673 \mathrm{~b}$ & $11094 \mathrm{a}$ & 14849 \\
\hline Promedio & $\mathbf{2 0 6}$ & $\mathbf{1 7 0 1}$ & $\mathbf{3 1 0 8}$ & $\mathbf{4 8 6 3}$ & $\mathbf{1 2 7 5 0}$ & $\mathbf{1 8 9 8 1}$ \\
\hline
\end{tabular}

* 50\% de Floración. DDE: días después de emergencia.

Letras diferentes en una misma columna son estadísticamente diferentes, $p<0,05$.

Cuadro 9b. Evolución de la biomasa del cultivo (kg/ha) para la Zafra 2.

\begin{tabular}{|l|c|l|l|l|c|c|}
\hline & MS 28 DDE & 49 DDE & 64 DDE & 71 DDE & Floración* & Cosecha \\
\hline IC30 & 324 & 1879 & 3739 a & 4275 & 16944 & 20628 \\
\hline RR & 369 & 1454 & $3229 \mathrm{~b}$ & 3229 & 12551 & 15451 \\
\hline Promedio & $\mathbf{3 4 6}$ & $\mathbf{1 6 6 7}$ & $\mathbf{3 4 8 4}$ & $\mathbf{3 7 5 2}$ & $\mathbf{1 4 7 4 8}$ & $\mathbf{1 8 0 3 9}$ \\
\hline
\end{tabular}

* $50 \%$ de Floración. DDE: días después de emergencia.

Letras diferentes en una misma columna son estadísticamente diferentes, $p<0,05$.

Cuadro 9c.Evolución de la biomasa del cultivo $(\mathrm{kg} / \mathrm{ha})$ para la Zafra 3.

\begin{tabular}{|l|c|c|c|c|c|l|}
\hline & 33 DDE & 46 DDE & 55 DDE & 67 DDE & Floración* & Cosecha \\
\hline IC30 & 414 & 953 & 1884 & $3269 \mathrm{a}$ & 9464 & 23410 \\
\hline RR & 386 & 1124 & 1496 & $2753 \mathrm{~b}$ & 10838 & 23184 \\
\hline Promedio & $\mathbf{4 0 0}$ & $\mathbf{1 0 3 8}$ & $\mathbf{1 6 9 0}$ & $\mathbf{3 0 1 1}$ & $\mathbf{1 0 1 5 1}$ & $\mathbf{2 3 2 9 7}$ \\
\hline
\end{tabular}

* 50\% de Floración. DDE: días después de emergencia.

Letras diferentes en una misma columna son estadísticamente diferentes, $p<0,05$.

fases posteriores del cultivo las emisiones comenzaron a declinar gradualmente hasta drenaje o cosecha. Las mayores tasas de emisión de metano para el tratamiento IC30 se encuentran entre 3948-4766 $\mathrm{g} / \mathrm{ha} / \mathrm{d}$, siendo significativamente superiores $(p=0,0016)$ a las registradas en el $\mathrm{RR}$ donde las tasas máximas de emisión variaron entre 2105$3189 \mathrm{~g} / \mathrm{ha} / \mathrm{d}$ (Figura 3b).

Para los tres años, las emisiones de metano tuvieron un pico máximo para el tratamiento IC30 a los 77 DDE en la Zafra 1, 92

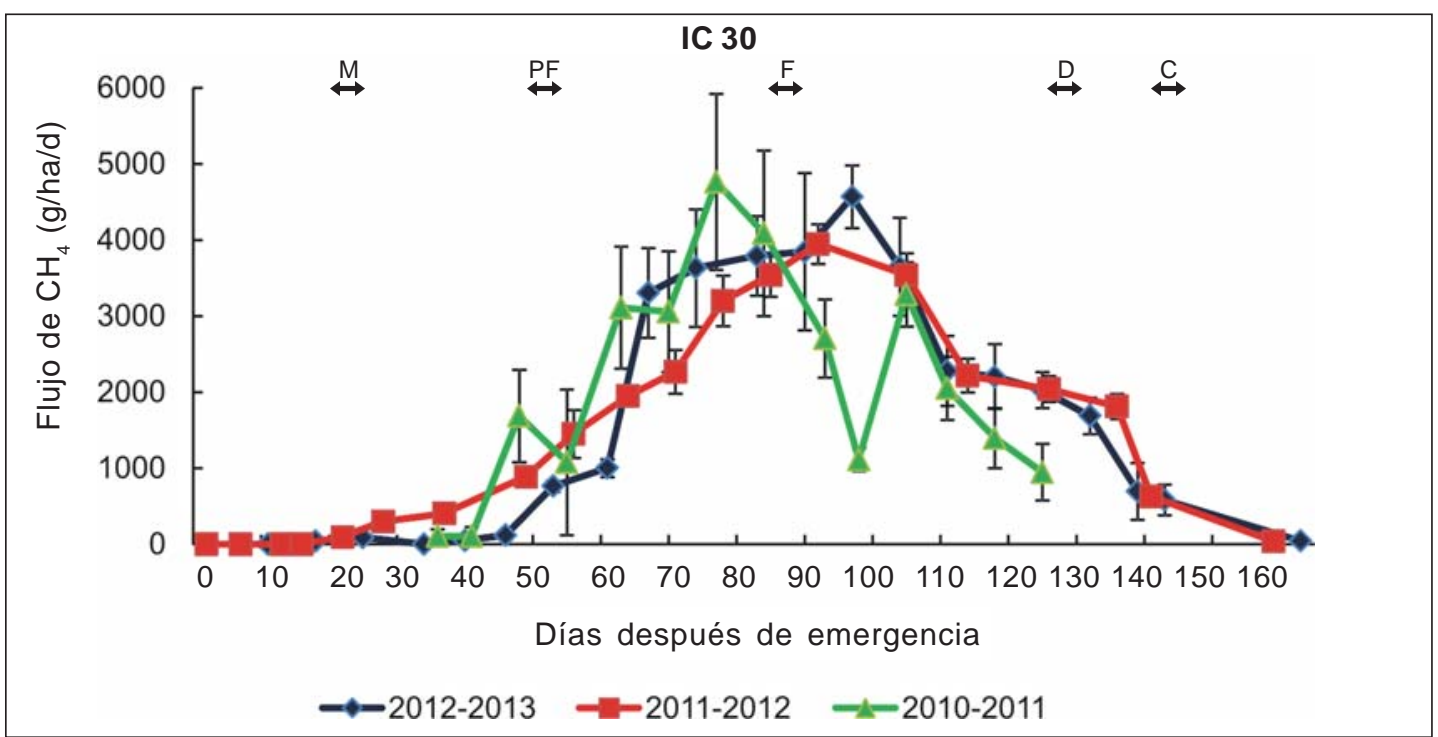

Figura 3a. Emisión de metano para el tratamiento IC30 en las tres zafras analizadas. M: Macollaje; PF: Primordio Floral; F: Floración; D: Drenaje; C: Cosecha 


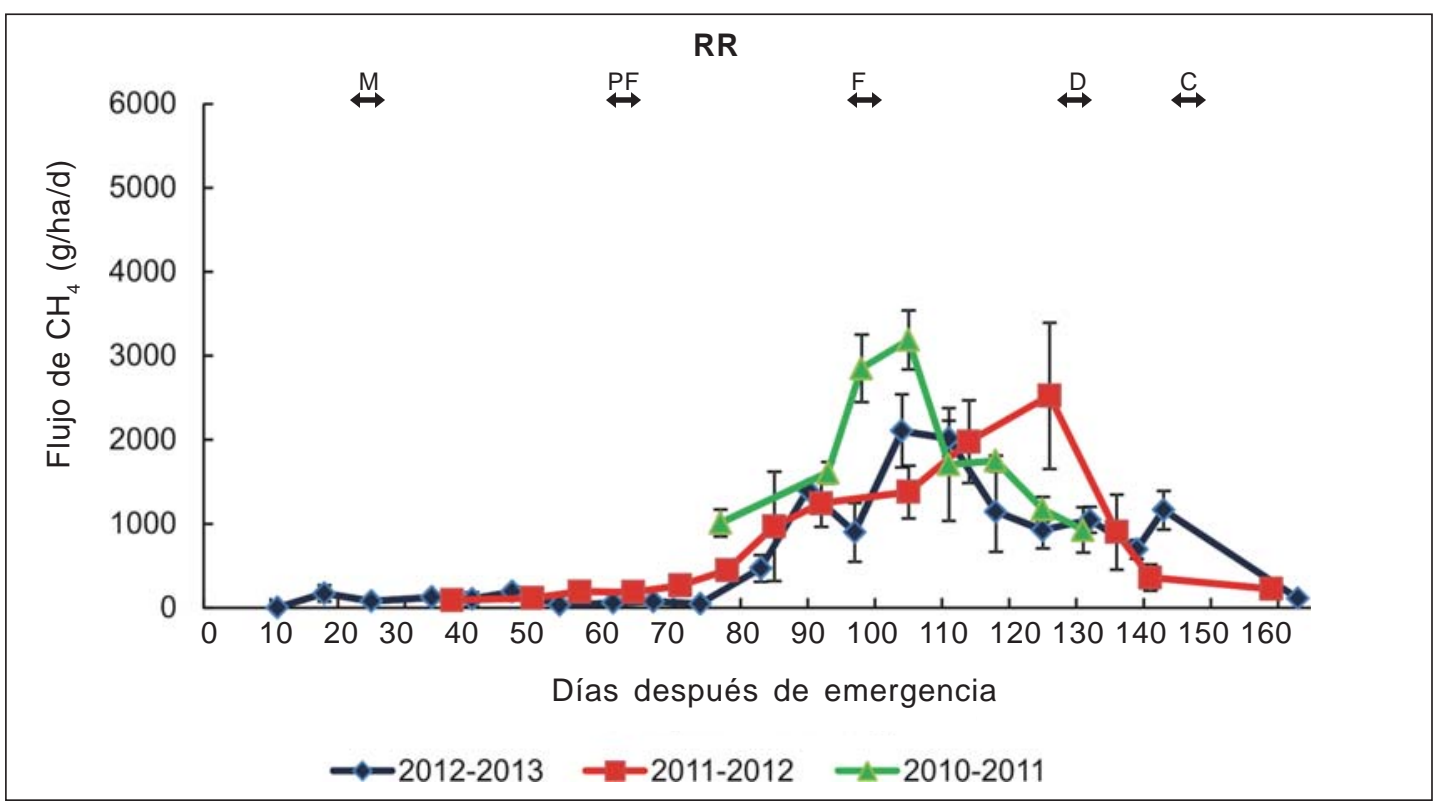

Figura 3a. Emisión de metano para el tratamiento IC30 en las tres zafras analizadas.

M: Macollaje; PF: Primordio Floral; F: Floración; D: Drenaje; C: Cosecha

DDE en la Zafra 2 y 97 DDE en la Zafra 3; en torno a ocho semanas luego de la inundación. Para RR los picos máximos se encontraron a los 105 DDE en la Zafra 1, 126 DDE en la Zafra 2 y 104 DDE en la Zafra 3; en torno a seis semanas luego de la inundación permanente. El mayor flujo se encontró en promedio siete días antes de floración en el IC30 y en el RR se registró 12 días después.

Los flujos totales de metano durante el ciclo del cultivo fueron en general mayores en el IC30 que los computados para el RR, siendo significativamente superiores en las dos últimas zafras analizadas (Cuadro 10). Estos mayores flujos de metano registrados en el IC30 se observaron incluso en el período en que ambos tratamientos estuvieron inundados (entre primordio floral y drenaje).

La baja tasa de emisión de $\mathrm{CH}_{4}$ observada durante la etapa vegetativa en el tratamiento IC30 puede ser resultado de la baja capacidad de transporte (desde el suelo a la atmósfera) que posee la planta debido al poco desarrollo que presentan las raíces y los macollos. Existe una alta correlación entre la biomasa de la planta (tanto de la parte aérea como de la subterránea), con el flujo

Cuadro 10. Rendimiento del cultivo y emisiones de metano y óxido nitroso según zafra.

\begin{tabular}{|c|c|c|c|c|c|c|}
\hline Zafra & Tratamiento & $\begin{array}{l}\mathrm{CH}_{4}^{(1)} \\
\text { (kg/ha) }\end{array}$ & $\begin{array}{c}\mathrm{CH}_{4}{ }^{(1)} \\
\text { (kg/ha CO }{ }_{2} \text { eq.) }\end{array}$ & $\begin{array}{c}\mathrm{N}_{2} \mathrm{O}^{(2)} \\
\text { (kg/ha) }\end{array}$ & $\begin{array}{c}\mathrm{N}_{2} \mathrm{O}^{(2)} \\
\text { (kg/ha } \mathrm{CO}_{2} \text { eq.) }\end{array}$ & $\begin{array}{c}\text { Rendimiento } \\
\text { (kg/ha) }\end{array}$ \\
\hline \multirow{2}{*}{1} & IC30 & 208,2 & 5205 & 0,3 & 81,2 & 11171 \\
\hline & $\mathrm{RR}$ & 93,3 & 2332,5 & 0,4 & 110,4 & 10170 \\
\hline \multirow{2}{*}{2} & IC30 & $249,4 a$ & $6234,1 a$ & 1 & 287,6 & $10387 a$ \\
\hline & $\mathrm{RR}$ & $106,3 b$ & $2657,5 b$ & 1,2 & 347,1 & $8700 b$ \\
\hline \multirow{2}{*}{3} & IC30 & $248,8 a$ & $6219,1 a$ & 0,6 & 192,8 & 9803 \\
\hline & $\mathrm{RR}$ & $95,7 b$ & $2392,2 b$ & 1,9 & 578,1 & 8992 \\
\hline
\end{tabular}

(1)Como la interacción entre zafra y tratamiento fue significativa, el análisis se realizó para cada zafra y por lo tanto las significancias que corresponden a la misma temporada acompañados de letras diferentes fueron significativamente diferentes al $p<0,05$.

(2) Emisiones de $\mathrm{N}_{2} \mathrm{O}$ para cada zafra no fueron significativamente diferentes. 
de emisión del $\mathrm{CH}_{4}$. Una mayor biomasa radical proporcionaría una mayor superficie para la difusión del $\mathrm{CH}_{4}$ desde el suelo reducido a las raíces, mientras que una mayor biomasa aérea facilitaría el transporte del gas a través de la planta (Baruah et al., 2010).

Algunos estudios reportan que la población y la estructura de la comunidad metanogénica se mantienen constantes en los diferentes períodos de crecimiento del cultivo de arroz, aún en condiciones de drenaje (Asakawa and Hayano, 1995; Watanabe et al., 2004, 2006, citados por Li et al., 2011), aunque su actividad comienza a aumentar poco después de la inundación y la magnitud con la que lo hace (la presencia de un pico de emisión temprano en la etapa vegetativa) dependería de la fermentación de la materia orgánica fácilmente degradable y de las condiciones de reducción del suelo por inundación (Li et al., 2011).

Cuando el cultivo de arroz se drena para la cosecha, a medida que los macroporos se van aireando, se va liberando la mayor parte del $\mathrm{CH}_{4}$ que estaba «atrapado» en el suelo. Este proceso culmina una vez que el suelo se airea totalmente (Neue et al., 1994, citado por Neue, 1997) y las emisiones de $\mathrm{CH}_{4}$ disminuyen a valores de cero (Peng et al., 2011). Las condiciones de aerobiosis que se dan luego del drenaje también promueven la oxidación del $\mathrm{CH}_{4}$ producido durante la inundación. Wang et al. (1993), observaron que la cantidad de metano atrapado es afectada por la textura del suelo. Los suelos de textura más arcillosa «atrapan» mayores cantidades de metano.

Tyagi et al. (2010) encontraron que el metano emitido durante todo el período del cultivo, fue superior para los tratamientos inundados permanentemente que para los tratamientos con drenajes a macollaje, drenajes a mitad del ciclo del cultivo y tratamientos con múltiples drenajes. La reduccion de emision de metano varió entre $12,4 \%$ y $71,8 \%$, que para los tratamientos de drenaje.

La formación de metano en el suelo es un proceso biológico mediado por anaerobiosis estricta en suelos reducidos. Antes de que la metanogénesis ocurra $\mathrm{NO}_{3}$, $\mathrm{Mn}, \mathrm{Fe}$ y $\mathrm{SO}_{4}$ del suelo deben ser reducidos
(Panamperuma, 1972; Patrick y Delaune, 1977; citados por Wang et al., 1993). Si un suelo contiene cantidades significativas de estos oxidantes, la formación de $\mathrm{CH}_{4}$ se verá restringida, utilizándose la materia orgánica o el carbono orgánico del suelo por otros reductores en lugar de las bacterias metanogénicas (Wang et al., 1993). Este autor constató también que las emisiones de metano son estimuladas en suelos ácidos y retardadas en suelos no ácidos o alcalinos.

Las emisiones totales de metano estimadas en este estudio se enmarcan dentro de los valores previamente publicados para arroz en países de clima templado. Se reportan valores de $634 \mathrm{~kg} / \mathrm{ha} \mathrm{CH}_{4}$ en sistemas inundados permanentemente (Hadi et al., 2010), $250 \mathrm{~kg} / \mathrm{ha} \mathrm{CH}_{4}$ (Cicerone et al., 1992), 112- $404 \mathrm{~kg} / \mathrm{ha} \mathrm{CH}_{4}$ (Schütz et al., 1989), entre $200-500 \mathrm{~kg} / \mathrm{ha} \mathrm{CH}_{4}$ para Japón, California, Italia y Korea. En sistemas con un manejo del cultivo más similar al nuestro (con siembra directa e inundación luego de emergencia) se reportan valores de 270 $\mathrm{kg} / \mathrm{ha} \mathrm{CH}_{4}$ (Rogers et al., 2012) y 340-423 $\mathrm{kg} / \mathrm{ha} \mathrm{CH}_{4}$ (Freire et al., 2013) en arrozales de Arkansas, USA y sur de Brasil, respectivamente.

La emisiones de $\mathrm{CH}_{4}$ en $\mathrm{kg} \mathrm{CO}$ eq. por $\mathrm{kg}$ de arroz cáscara ( $\mathrm{CO}_{2}$ eq./kg grano) promedio fueron de 0,57 para IC30 y 0,27 para $\mathrm{RR}$, valores que se encuentran entre los reportados a nivel mundial: 0,50 y 0,55 para USA y Tailandia, respectivamente (CarlssonKanyama, 2007); 0,64 en India (Garg et al., 2006 citado por Carlsson-Kanyama, 2007) y 0,59 en Japón (Breiling et al., 2005, citado por Carlsson - Kanyama, 2007).

\section{Potencial redox}

El potencial redox (Eh) es un indicador de las condiciones de reducción y oxidación en el que se encuentra el suelo e indirectamente de las condiciones de aerobiosis (mayor oxidación) o anaerobiosis (mayor reducción) en el que se encuentra el sistema. Estas condiciones de oxidación/reducción afectan directamente a los microorganismos que regulan las emisiones de gases y por lo 
tanto han sido objeto de análisis en este tipo de estudios. Towprayoon et al. (2005), encontraron que los datos de Eh fueron significativamente superiores durante el período seco (oxidación) similar a lo encontrado en este estudio (Cuadro 11 y Figura 4).

En este estudio se constató la relación inversa entre emisiones de metano y el potencial redox del suelo. Las emisiones comenzaron a aumentar a medida que el Eh del suelo disminuia (condiciones más anaeróbicas) y una vez drenadas las parcelas (fin de riego) las emisiones disminuían junto con el aumento del potencial redox del suelo (Towprayoon et al., 2005).

El parámetro en estudio, Eh, se comportó de manera diferente en los dos tratamientos (Cuadro 11 y Figura 4). Se encontró que en el tratamiento IC30 el potencial redox estuvo por encima de $+300 \mathrm{mV}$ previo a la inundación permanente y luego de la misma disminuyó hasta $-100 \mathrm{mV}$ en un período de 30 días (Figura 4). Por otro lado, los valores de Eh encontrados para el tratamiento RR disminuyeron gradualmente hasta $100 \mathrm{mV}$ a los 46 días después de emergencia. Esto fue seguido por un transitorio incremento y decrecimiento del potencial redox durante el período en el que se realizaron los riegos
Cuadro 11. Potencial Redox y temperatura del suelo para la Zafra 3.

\begin{tabular}{|c|c|c|c|c|}
\hline \multirow{2}{*}{ DDE } & \multicolumn{2}{|c|}{ IC30 } & \multicolumn{2}{c|}{ RR } \\
\cline { 2 - 5 } & $\mathbf{m V}$ & ${ }^{\circ} \mathbf{C}$ & $\mathbf{m V}$ & ${ }^{\circ} \mathbf{C}$ \\
\hline 11 & 359,0 & 29,7 & 353,2 & 30 \\
18 & 282,9 & 33,4 & 319,4 & 34 \\
25 & 323,0 & 27,1 & 319,1 & 28 \\
40 & 157,1 & 29,2 & 213,1 & 29 \\
46 & 112,3 & 24,7 & 132,2 & 24 \\
53 & 43,9 & 22,2 & 252,4 & 22 \\
61 & $-54,3$ & 26,0 & 114,9 & 25 \\
68 & $-81,3$ & 24,9 & 197,3 & 25 \\
74 & $-105,3$ & 23,9 & 84,5 & 24 \\
83 & $-107,1$ & 21,3 & 26,5 & 21 \\
90 & $-117,8$ & 26,7 & $-41,3$ & 27 \\
97 & $-98,2$ & 23,0 & $-100,6$ & 23 \\
104 & $-123,5$ & 25,3 & $-117,9$ & 26 \\
111 & $-118,5$ & 21,1 & $-102,0$ & 34 \\
118 & $-105,5$ & 21,8 & $-107,3$ & 21 \\
125 & $-124,5$ & 22,8 & $-134,2$ & 23 \\
132 & $-113,9$ & 18,2 & $-117,3$ & 18 \\
139 & $-4,2$ & 19,1 & $-108,5$ & 20 \\
143 & 143,7 & 20,1 & $-113,7$ & 20 \\
163 & 270,5 & 18,7 & 217,3 & 20 \\
\hline
\end{tabular}

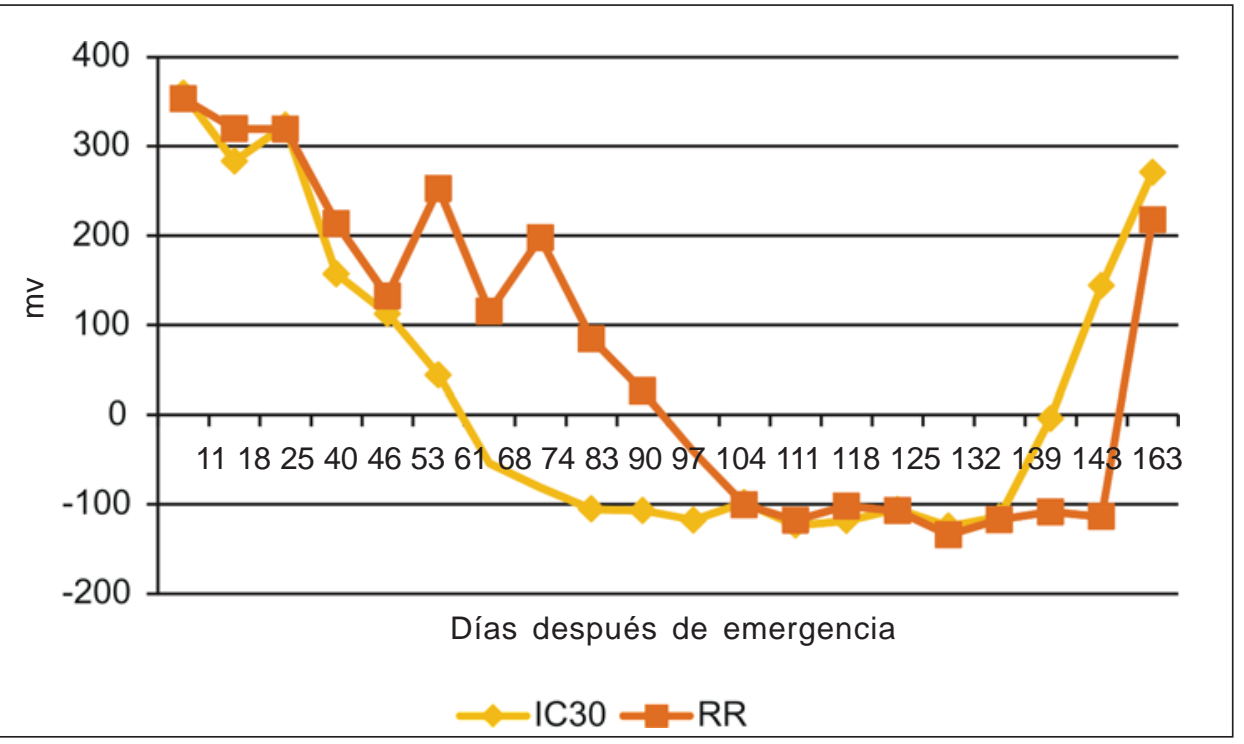

Figura 4. Evolución del potencial redox para el tratamiento IC30 y RR en la Zafra 3. 
intermitentes de este tratamiento, hasta la inundación permanente, momento en el cual el Eh comienza a ser negativo. Esta fluctuación de Eh se corresponde con las mínimas emisiones de $\mathrm{CH}_{4}$ en RR (ver Figura 3b), período en el cual el potencial redox del suelo no fue lo suficientemente bajo para favorecer la actividad de las bacterias metanogénicas. Como consecuencia las emisiones de $\mathrm{CH}_{4}$ en el tratamiento RR fueron atrasadas en el tiempo, respecto a las de los tratamientos IC30.

Se necesitaron casi dos semanas, en el período de inundación permanente, para que las bacterias metanogénicas iniciaran su actividad y las emisiones de $\mathrm{CH}_{4}$ aumentaran con el paso del tiempo, para que, en ambos tratamientos, se alcanzara un pico máximo, alrededor de dos meses después, cuando el Eh tuvo el mínimo valor. Los valores de metano fluctuaron y decrecieron gradualmente hasta cosecha (ver Figuras 3a, 3 b y 4$)$.

El patrón de emisión de metano mostró, a diferencia de otros estudios, un solo pico máximo. Este patrón de emisión de solamente un pico máximo en la fase tardía de reproducción se puede atribuir a las prácticas agronómicas utilizadas que involucran varios factores. En primer lugar, la ausencia de incorporación de enmiendas orgánicas, las cuales tienden a aumentar la emisión de metano, como lo reportan Watanabe et al. (1999) e Itoh et al. (2011), condiciones inadecuadas para la metanogénesis, durante los 30 días en los que el suelo no está inundado y por último, condiciones de barbecho no inundado (Zhang et al., 2011) ocupada con pasturas invernales. En el período de floración, los tejidos en descomposición y los exudados de las raíces, que son fuentes rápidas de carbono, se encuentran en grandes cantidades y al mismo tiempo, los sistemas de transporte de gases en las plantas estan bien desarrolladas (Wassmann et al., 2002). Éstos son factores que llevan a que se produzcan mayores emisiones de metano en este estado reproductivo del cultivo (Mitra et al., 2005). Sumado a esto, las condiciones reducidas del suelo creadas por la inundación permanente promueven la degradación anaeróbica de la materia orgánica presente en el suelo y por lo tanto aumenta la disponibilidad de sustratos para las bacterias metanogénicas, productoras de metano (Towprayoon et al., 2000).

La alternancia de las condiciones de suelo húmedo y seco retrasa la producción de metano en relación a los tratamientos inundados (ver Figuras 3a y 3b). Este patrón de retraso en la producción de metano se observa también en tratamientos con drenaje en la mitad del ciclo del cultivo o en tratamientos de drenajes múltiples (Towprayoon et al., 2005; Tyagi et al., 2010; Itoh et al., 2011). Esta disminución puede ser debida a la aireación generada por el secado del suelo, que suprime la actividad metanogénica e incluso puede aumentar la metanotrófica. Sin embargo, algunos autores señalan la cautela en cuanto a la eficacia en la mitigación de las emisiones de metano (Itoh et al., 2011) y han planteado la hipótesis de que, en ausencia de un residuo anterior (rastrojo de arroz), el drenaje a mitad del ciclo puede promover el crecimiento de las raíces del arroz, provocando a su vez, un aumento en la emisión de metano a finales del ciclo del cultivo. En nuestro estudio, sin embargo, el $\mathrm{RR}$ fue eficaz en el retraso y la reducción de las emisiones totales de metano.

En las Figuras $5 a$ y $5 b$ se observa el patrón de emisión de óxido nitroso para los dos tratamientos de riego en las tres zafras analizadas. No existió un patrón claro de emisión de $\mathrm{N}_{2} \mathrm{O}$ para los distintos tratamientos ni para las zafras analizadas. Hasta 30 días de emergencia, cuando el tratamiento IC30 se inunda, los dos tratamientos se comportan de forma similar, registrándose uno o dos picos de emisión de óxido nitroso en todas las zafras.

En la Zafra 2 el pico máximo coincidió luego de un baño ( $65 \mathrm{~g} / \mathrm{ha} / \mathrm{d} \mathrm{N}_{2} \mathrm{O}$ ). Según algunos autores (Khalil y Baggs, 2005; Skiba y Ball, 2002; Guo et al., 2010) estas emisiones en suelos húmedos se deben principalmente a los procesos de desnitrificación.

El comportamiento esporádico de los flujos de $\mathrm{N}_{2} \mathrm{O}$ han sido reportados en trabajos anteriores en sistemas en donde se incluye el cultivo de arroz (Zhao et al., 2011; Pittelkow et al., 2013). Existen numerosos factores involucrados en el control de las 


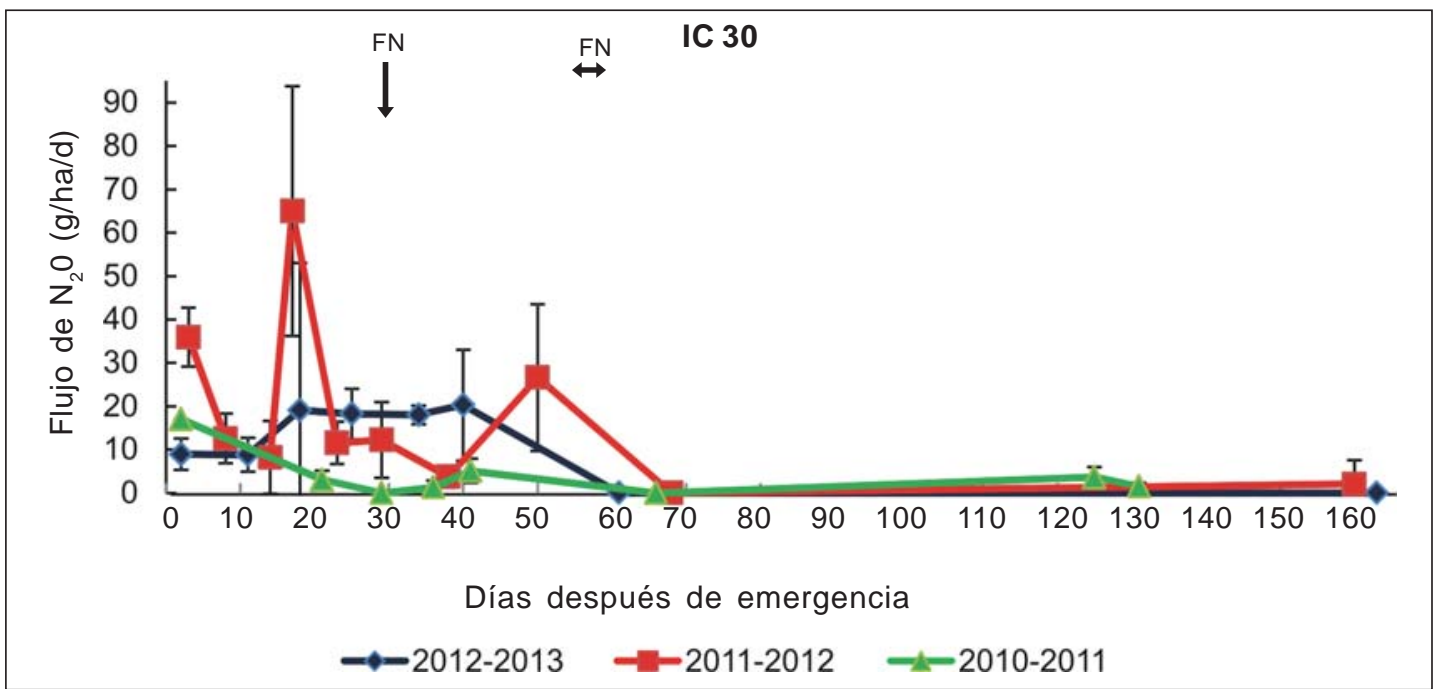

Figura 5a. Emisión de óxido nitroso para el tratamiento IC30 en las tres zafras analizadas. FN: Fertilización nitrogenada.

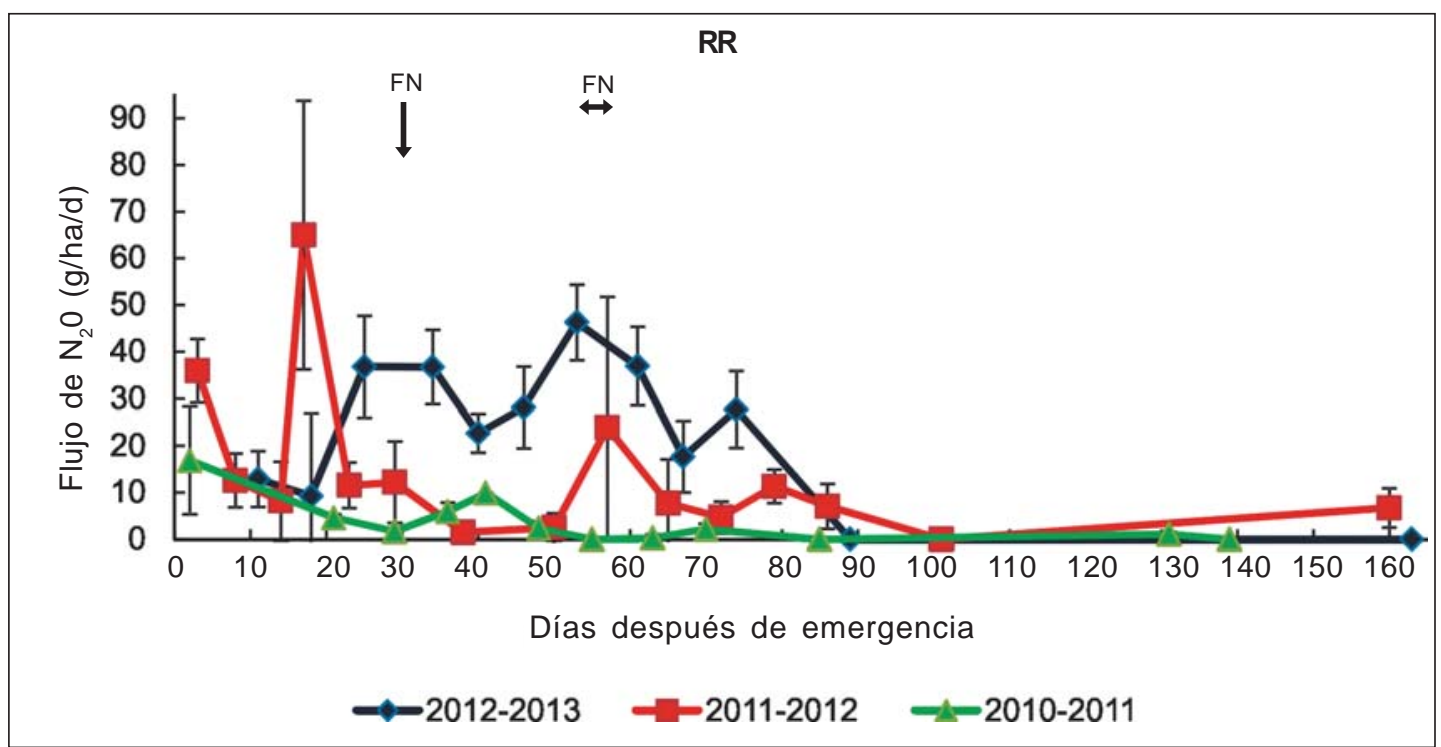

Figura 5b. Emisión de óxido nitroso para el tratamiento RR en las tres zafras analizadas.

FN: Fertilización nitrogenada.

emisiones de $\mathrm{N}_{2} \mathrm{O}$ desde el suelo, los cuales contribuyen a la enorme variación espacio temporal que existen en los ensayos de campo (Bakken y Dörsch, 2007). Como consecuencia de la variación espacio-temporal que existe, Bakken et al. (2012) establecieron que el poder de las pruebas estadísticas de tales experimentos es bajo.

En general, las emisiones de $\mathrm{N}_{2} \mathrm{O}$ mostraron un comportamiento opuesto respecto a $\mathrm{CH}_{4}$ en el transcurso del ciclo del cultivo, registrando un pico de emisión previo a la inundación del cultivo (ver Figura 4). Para el tratamiento IC30, las emisiones estuvieron más asociadas al régimen de agua (a la alternancia de episodios de anaerobiosis/aerobiosis generados por riegos o lluvias). La emisión de $\mathrm{N}_{2} \mathrm{O}$ en el cultivo de arroz es causada por nitrificación en suelos oxidados y desnitrificación en suelos semi-reducidos, por lo que luego de una lluvia o de un riego es esperable que los flujos de este gas se incrementen. Una vez inundado el cultivo y en condiciones favorables para la desnitrifi- 
cación, se restringe la formación de $\mathrm{N}_{2} \mathrm{O}$ y su emisión (Towprayoon et al., 2005).

En el tratamiento RR los flujos de $\mathrm{N}_{2} \mathrm{O}$ se detectaron hasta los 90 días luego de la emergencia del cultivo, mientras que en el tratamiento IC30 hasta los 60 días. La alternancia del suelo húmedo y seco crea un ambiente favorable para ambos procesos, nitrificación y desnitrificación (Zou et al., 2007), probablemente por una mayor disposición de carbono del suelo liberada por la materia orgánica, favoreciendo consecuentemente el proceso de desnitrificación, que es principalmente heterotrófico.

La emisión de $\mathrm{N}_{2} \mathrm{O}$ permaneció cercana a cero luego de 20 días en inundación permanente para ambos tratamientos. Durante este período de inundación, donde el suelo estuvo anegado y los valores de potencial redox fueron negativos, (ver Figura $5 a$ y $5 b$ ), no hubo emisiones de $\mathrm{N}_{2} \mathrm{O}$ probablemente debido a una mayor reducción hasta $\mathrm{N}_{2}$ (Granli and Bockman, 1994). Algunos autores (Johnson-Beebout, S. et al., 2009) reportan que las emisiones de óxido nitroso, luego de 10 días en tratamientos de inundación continua, son muy pequeñas.

Linquist et al. (2012), analizaron publicaciones en donde se reportaban emisiones de GEI de cereales, encontrando que para el arroz que correspondía a una emisión promedio de $0,88 \mathrm{~kg} / \mathrm{ha} /$ zafra $_{2} \mathrm{O}$. Los resultados de este estudio se encuentran también en el entorno de estas cantidades $(0,6 \mathrm{~kg} /$ ha/zafra $\mathrm{N}_{2} \mathrm{O}$ para IC30 y $1,2 \mathrm{~kg} / \mathrm{ha} /$ zafra $\mathrm{N}_{2} \mathrm{O}$ para el RR). Las condiciones de humedad en el suelo y el manejo de la fertilización son los factores principales en la determinación de las emisiones de $\mathrm{N}_{2} \mathrm{O}$ en suelos arroceros (Guo y Zhou, 2007). Sin embargo, en estos estudios los picos de emisión de $\mathrm{N}_{2} \mathrm{O}$ no estuvieron necesariamente relacionados con los eventos de fertilización nitrogenada (Figura 5a y 5b). Bakken et al. (2012) encontraron al igual que en el presente estudio que cuando los niveles de fertilización nitrogenada se manejan dentro de los rangos reales de necesidad del cultivo los flujos de $\mathrm{N}_{2} \mathrm{O}$ se correlacionan pobremente con los momentos de fertilización. La fertilización con $\mathrm{N}$ según la demanda del cultivo minimiza el exceso de nitrógeno en el suelo y por lo tan- to reduce las emisiones de óxido nitroso (Matson et al., 1998). Durante macollaje el cultivo de arroz se encuentra en activo crecimiento, por lo que la cantidad de nitrógeno mineral en el suelo que puede perderse es mínima.

La fertilización particionada utilizada en este estudio, método recomendado para la aplicación del fertilizante en Uruguay, probablemente aumentó la eficiencia de uso del nitrógeno. Es claramente conocida la relación inversa entre las emisiones de $\mathrm{N}_{2} \mathrm{O}$ y la eficiencia del nitrógeno (Dalal et al., 2003). La recuperación total del nitrógeno del fertilizante en las plantas de arroz puede ser de $40 \%$ cuando el fertilizante se divide en más de una aplicación, en comparación con una única aplicación del fertilizante, en el mismo campo de arroz (Irisarri et al., 2007).

\section{Productividad y eficiencia del uso de agua}

En el Cuadro 12 se muestra el uso del agua para el cultivo y la productividad de la misma (kg de arroz por $\mathrm{m}^{3}$ de agua). La productividad del agua se define como la cantidad de agua aplicada (riego) o total (riego más precipitación) por unidad de rendimiento de grano.

En términos generales en la Zafra 3 se requirió menor cantidad total de agua de riego durante el período entre siembra e inundación permanente debido a las precipitaciones y su distribución en el tiempo. De manera opuesta, la Zafra 1 se caracterizó por presentar menos días de lluvia en dicho período, mientras que el patrón de lluvias en la Zafra 2 fue irregular, sin lluvias luego de la siembra y luego de períodos lluviosos. Se utilizaron cantidades significativamente menores de agua de riego para RR en la Zafra $3,20 \%$ inferior, respecto a IC30 y se observa la misma tendencia para las Zafras 1 y 2 .

No se encontraron diferencias significativas en rendimiento entre los tratamientos, excepto en la Zafra 2, donde IC30 obtuvo un rendimiento significativamente mayor (ver Cuadro 10).

Por otro lado, la productividad del agua de riego fue significativamente mayor en $\mathrm{RR}$ 
Cuadro 12. Consumo y productividad del agua para el cultivo de arroz bajo los dos tratamientos y en las tres zafras.

\begin{tabular}{|c|c|c|c|c|c|}
\hline Zafra & Tratamiento & $\begin{array}{c}\text { Agua de riego } \\
\text { aplicada (m³a }{ }^{(1)}\end{array}$ & $\begin{array}{l}\text { Agua total } \\
\left(\mathrm{m}^{3} / \mathrm{ha}\right)^{*}\end{array}$ & $\begin{array}{l}\text { Productividad del } \\
\text { agua de riego } \\
\left(\mathrm{kg} / \mathrm{m}^{3} / \mathrm{ha}\right)\end{array}$ & $\begin{array}{l}\text { Productividad del } \\
\text { agua total } \\
\left(\mathrm{kg} / \mathrm{m}^{3} / \mathrm{ha}\right)\end{array}$ \\
\hline \multirow{2}{*}{1} & IC30 & 11208 & 15905 & 1,01 & 0,71 \\
\hline & $\mathrm{RR}$ & 7708 & 12666 & 1,35 & 0,81 \\
\hline \multirow{2}{*}{2} & IC30 & 8278 & 11657 & 1,23 & 0,82 \\
\hline & $\mathrm{RR}$ & 7017 & 10667 & 1,25 & 0,87 \\
\hline \multirow{2}{*}{3} & IC30 & $6072 a$ & $11103 a$ & $1,65 b$ & 0,88 \\
\hline & $\mathrm{RR}$ & $4776 \mathrm{~b}$ & $10622 b$ & $2,00 a$ & 0,89 \\
\hline
\end{tabular}

*Agua de riego + precipitaciones.

(1) Como la interacción entre zafra y tratamiento fue significativa, el análisis se realizó para cada zafra y por lo tanto las significancias que corresponden a la misma temporada acompañados de letras diferentes fueron significativamente diferentes al $p<0,05$.

$\left(2 \mathrm{~kg} / \mathrm{m}^{-3}\right)$ en la Zafra 3 (Cuadro 12), con una mejora en la eficiencia del uso del agua de riego cercana al $20 \%$. En trabajos anteriores, en sistemas arroceros del sudeste asiático, se indican niveles de mejora en la eficiencia del uso del agua similares con manejos del agua de la misma índole (Chapagain y Yamaji, 2010; Thakur et al., 2011).

Los resultados obtenidos en este estudio muestran que el RR permite un mejor aprovechamiento del agua de lluvia en un año estándar (precipitaciones regulares) aumentando la productividad del agua.

Las tecnologías de ahorro del agua, como lo es la alteración de períodos secos y húmedos, sin dejar agotar completamente el agua del suelo, son herramientas que permitirían reducir las cantidades de agua utilizadas para el cultivo en relación a inundaciones permanentes, sin reducir el rendimiento significativamente (Bouman y Tuong, 2001; Tabbal et al., 2002; Yao et al., 2012; Peng y Bouman, 2007).

Algunos autores aseguran que la gran variabilidad encontrada en la performance de los tratamientos de ahorro del agua (similares al RR en el presente estudio), se deben a las distintas propiedades del suelo y condiciones hidrológicas y afirman que la variedad de arroz utilizada puede jugar también un papel fundamental, ya que existen cultivares con mayor adaptación a este tipo de manejos del agua (Yao et al., 2012; Peng y Bouman, 2007).
Sin embargo, instrumentar un manejo de este tipo con alternancias de condiciones húmedas y secas pero sin dejar agotar totalmente el agua del perfil del suelo tiene una implicancia importante en los diseños de los sistemas de riego, ya que el agua de riego debe ser entregada en la chacra de forma regular y precisa. Para el rediseño de los sistemas de riego debería existir un incentivo económico que reditúe las inversiones para la optimización y reciban un beneficio por la aplicación de tecnologías de ahorro de agua, incluso cuando sus rendimientos pudieran verse mínimamente disminuidos. La adopción de dicha tecnología permitiría el ahorro de agua, lo que posibilitaría la expansión del cultivo (Bouman y Tuong, 2001).

\section{Potencial de calentamiento global en relación a los tratamientos de riego (PCG)}

El gas que mayoritariamente contribuyó al PCG fue el metano en ambos tratamientos de riego, 97 y $88 \%$ en promedio para IC30 y RR respectivamente (Cuadro 13). Esto concuerda con estudios anteriores en donde se muestra que las emisiones de $\mathrm{N}_{2} \mathrm{O}$ en términos de PCG, como $\mathrm{CO}_{2}$ equivalente, son mucho menores a las de $\mathrm{CH}_{4}$ (Itoh et al., 2011; Pittelkow et al., 2013). Johnson Beebout et al. (2009) encontraron que la reducción simultánea de la emisión de ambos gases, $\mathrm{CH}_{4}$ y $\mathrm{N}_{2} \mathrm{O}$, no pueden mantenerse 
Cuadro 13. Contribución del metano y óxido nitroso al potencial de calentamiento global (PCG) en cada tratamiento de riego para las tres zafras.

\begin{tabular}{|c|c|c|c|c|}
\hline \multirow{2}{*}{ Zafra } & \multicolumn{2}{|c|}{$\% \mathrm{CH}_{\mathbf{4}}$ (kg/ha $\mathrm{CO}_{2}$ eq.) } & \multicolumn{2}{c|}{$\% \mathrm{~N}_{\mathbf{2}} \mathrm{O}$ (kg/ha CO $\mathbf{2}$ eq.) } \\
\cline { 2 - 5 } & $\mathrm{IC} 30$ & $\mathrm{RR}$ & $\mathrm{IC} 30$ & $\mathrm{RR}$ \\
\hline 1 & 98 & 95 & 2 & 5 \\
2 & 96 & 88 & 4 & 12 \\
3 & 97 & 81 & 3 & 19 \\
\hline Promedio & $\mathbf{9 7}$ & $\mathbf{8 8}$ & $\mathbf{3}$ & $\mathbf{1 2}$ \\
\hline
\end{tabular}

debido a los cambios del potencial redox del suelo. Cuando las emisiones de $\mathrm{CH}_{4}$ y $\mathrm{N}_{2} \mathrm{O}$ son integradas y expresadas como $\mathrm{CO}_{2}$ equivalente, el tratamiento RR disminuyó el PCG en un $50 \%$ (Cuadro 14).

Conjuntamente con la importancia de las emisiones de GEI de los arrozales, el rendimiento del cultivo es de suma trascendencia, ya que es lo que determina el ingreso económico de la empresa. Los rendimientos del cultivo de arroz en el Uruguay se encuentran dentro de los más altos del mundo y la estrategia del manejo del agua debe evitar que este sistema de alta productividad de cultivo se vea afectado. Como se muestra en la tabla 10, a pesar de que únicamente en la Zafra 2 el rendimiento de grano fue significativamente menor para el tratamiento $\mathrm{RR}$ en relación al IC30, los rendimientos en las otras zafras fueron también menores.

De manera de poder conjugar el rendimiento productivo con las emisiones de gases se determinó el potencial de calentamiento global de cada manejo del riego por unidad de rendimiento lo se que conoce como PCG a escala de rendimiento (Pittelkow et al., 2013). EI PCG a escala de rendimiento (PCGR) indica por lo tanto los $\mathrm{kg}$ de $\mathrm{CO}_{2}$ equivalente emitidos por $\mathrm{kg}$ de arroz producido. En el Cuadro 14 se muestra el PCGR para cada zafra en cada uno de los manejos del riego.

EI PCGR mostró una reducción promedio cercana al $50 \%$ para el sistema de riego alternativo, RR, frente al tratamiento de inundación tradicional, IC30 (Figura 6). Estos resultados concuerdan con los encontrados por Yagui et al. (2010) y Towprayoon et al. (2005), quienes encontraron que los PCG de los tratamientos inundados permanentemente fueron superiores a los que presentaban múltiples drenajes durante el ciclo del cultivo o los que se drenaban a mitad del ciclo del cultivo. Estos resultados determinan que el manejo del riego RR con períodos de alternancia de anaerobiosos y aerobiosis podría ser auspicioso para la mitigación de GEI en arroz.

Cuadro 14. PCG y PCGR para las tres zafras.

\begin{tabular}{|c|c|c|c|c|c|}
\hline Zafra & Tratamiento & $\begin{array}{c}\text { PCG (kg/ha } \\
\text { CO }_{2} \text { eq.) }\end{array}$ & $\begin{array}{c}\text { Reducción } \\
\text { PCG (\%) }\end{array}$ & $\begin{array}{c}\text { PCG a escala del } \\
\text { rendimiento (kg/ha } \\
\text { CO } \mathbf{2} \text { eq./kg grano } \\
\text { de arroz) }\end{array}$ & $\begin{array}{c}\text { Reducción del PCG a } \\
\text { escala del rendimiento } \\
\text { (\%) }\end{array}$ \\
\hline \multirow{2}{*}{1} & IC30 & 5286 & & 0,47 & \\
& RR & 2443 & 54 & 0,24 & 49 \\
\hline \multirow{2}{*}{2} & IC30 & 6522 & & 0,63 & 45 \\
& RR & 3005 & 54 & 0,35 & 49 \\
\hline \multirow{2}{*}{3} & IC30 & 6412 & & 0,65 & \\
& RR & 2970 & 54 & 0,33 & \\
\hline
\end{tabular}




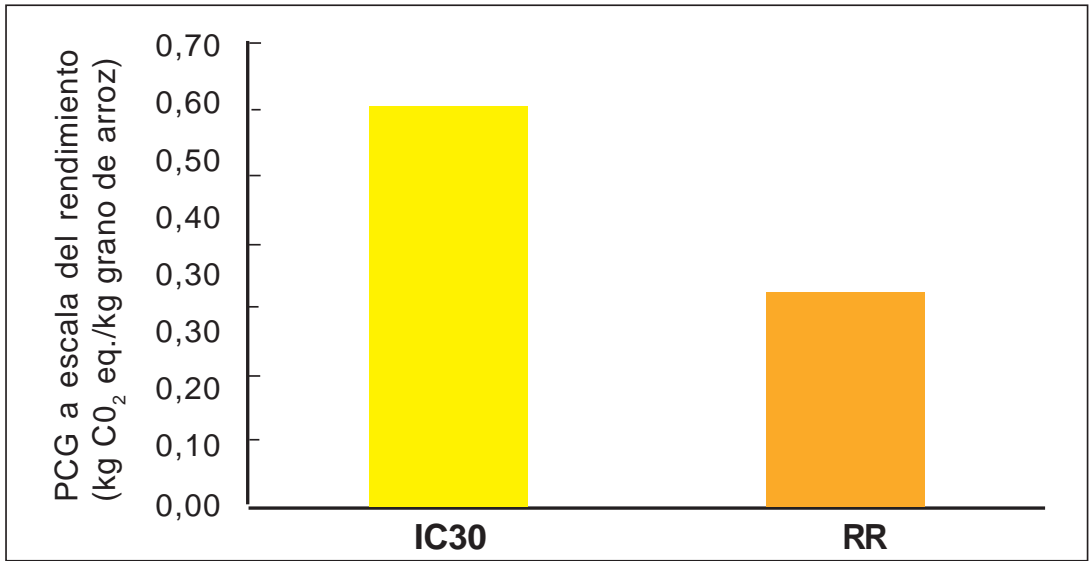

Figura 6. Potencial de calentamiento global por $\mathrm{kg}$ de arroz producido para dos manejos del agua diferentes.

\section{CONCLUSIONES}

En el Uruguay, bajo prácticas de manejo estándares (IC30) para el cultivo de arroz y utilizando la variedad EI Paso 144, las emisiones de metano y óxido nitroso fueron de $235 \mathrm{~kg} / \mathrm{ha} \mathrm{CH}_{4}$ y $1 \mathrm{~kg} / \mathrm{ha} \mathrm{N} \mathrm{O}_{2} \mathrm{O}$. (desde emergencia hasta cosecha del cultivo). La emisión de $\mathrm{N}_{2} \mathrm{O}$ durante el ciclo del cultivo fue baja y su contribución al PCG fue de tan solo $3 \%$, por lo tanto el principal GEI emitido por el arroz fue el $\mathrm{CH}_{4}$.

Los datos de estimaciones de emisiones totales de metano de este estudio se ubican dentro de las de menor rango a las publicadas para arroz en países de clima templado. Se reportan valores de $634 \mathrm{~kg} / \mathrm{ha} \mathrm{CH}_{4}$ en sistemas inundados permanentemente (Hadi et al., 2010), $250 \mathrm{~kg} / \mathrm{ha} \mathrm{CH}_{4}$ (Cicerone et al.,

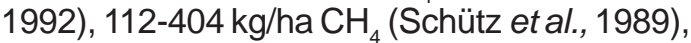
entre $200-500 \mathrm{~kg} / \mathrm{ha} \mathrm{CH}_{4}$ para Japón, California, Italia y Korea. En sistemas con un manejo del cultivo más similar al nuestro (con siembra directa e inundación luego de emergencia) se reportan valores de $270 \mathrm{~kg} / \mathrm{ha} \mathrm{CH}_{4}$ (Rogers et al., 2012) y $340-423 \mathrm{~kg} / \mathrm{ha} \mathrm{CH}$ (Freire et al., 2013) en arrozales de Arkansas, USA y sur de Brasil, respectivamente.

Las emisiones de $\mathrm{CH}_{4}$ y $\mathrm{N}_{2} \mathrm{O}$ mostraron un comportamiento opuesto durante el transcurso del ciclo del cultivo: la emisión de $\mathrm{N}_{2} \mathrm{O}$ fue máxima previo a la inundación, en etapa vegetativa, mientras que la mayor concentración de $\mathrm{CH}_{4}$ se alcanzó en período reproductivo, en torno a floración.
El manejo del agua en el cultivo de arroz afectó la tasa de emisión de los gases evaluados. La aplicación del sistema de riego restringido o alternante en la fase vegetativa (tratamiento RR), el cual reduce el período bajo inundación disminuyo las emisiones GEI. El tratamiento RR presentó valores de emisión promedio acumulado de $\mathrm{CH}_{4}$ de 98,4 $\mathrm{kg} / \mathrm{ha} \mathrm{CH}_{4}$, un 55\% menor en relación al IC30, mientras que no se observaron diferencias significativas en las emisiones de óxido nitroso entre tratamientos. Por lo tanto, este manejo del agua en el cultivo se presenta como auspicioso para atenuar las emisiones de metano.

En relación al rendimiento de grano, los resultados mostraron que durante dos de los tres años evaluados no se encontraron diferencias significativas del rendimiento del cultivo de arroz respecto a los manejos del riego. Sin embargo, el manejo RR presentó un rendimiento significativamente menor en uno de los años evaluados, por consiguiente, este manejo alternativo del riego podría comprometer la producción de grano del cultivo.

En cuanto a la totalidad de agua aplicada y la productividad de la misma, no se encontraron diferencias en dos de los años evaluados, mientras que el tratamiento IC30 presentó mayores niveles de agua aplicada y menor productividad del agua en uno de ellos.

En lo que respecta al Potencial de Calentamiento Global y el PCG por kg de arroz producido, se observó una reducción del $54 \%$ y del $48 \%$, respectivamente por el tra- 
tamiento RR en comparación con el manejo tradicional (IC30).

Los valores de emisiones de metano por kg de arroz cáscara producido, que combinan los aspectos de productividad y emisiones generadas se encuentran entre los reportados a nivel mundial. El tratamiento de riego IC30 presento un valor promedio de 0,57 $\mathrm{kgCO}$ eq./kg grano mientras que el RR fue de $0,27 \mathrm{kgCO}, \mathrm{eq} / \mathrm{kg}$ grano. CarlssonKanyama (2007), reportan valores de 0,50 y $0,55 \mathrm{kgCO}_{2}$ eq. $/ \mathrm{kg}$ grano para USA y Tailandia, respectivamente; $0,64 \mathrm{kgCO}_{2}$ eq. $/ \mathrm{kg}$ grano en India y $0,59 \mathrm{kgCO}_{2}$ eq. $/ \mathrm{kg}$ grano para Japón.

Estos hallazgos sugieren que el manejo del riego con déficit controlado (RR) puede ser una opción efectiva para reducir la emisión de gases de efecto invernadero en sistemas arroceros del Uruguay. Sin embargo este manejo más restringido del agua requiere de un monitoreo mucho más controlado del riego de manera de generar condiciones de déficit hídrico que no depriman los rendimientos.

Por lo tanto, las consideraciones globales de las incertidumbres vinculadas a los aspectos productivos así como de los mayores requerimientos de monitoreo y control de los sistemas de riego deben de ser profundamente analizadas a la hora de optar por un manejo del agua más restringido.

De acuerdo al Inventario Nacional de Emisiones de Gases de Efecto Invernadero, el cual utiliza factores de emisión, metodologías y otros parámetros de las directrices del IPCC 2006, se estima una emisión total de metano en Uruguay para el 2004 de 35,4 Kton. Según los resultados encontrados en este trabajo, las emisiones totales de metano serían sensiblemente mayores a las estimadas en el inventario 2004.

Dado que las emisiones de gases del propio cultivo son el mayor contribuyente a la huella de carbono global del sector arrocero Uruguayo (Becoña et al., 2013) determinan la necesidad y la importancia de continuar los avances en los estudios de los factores de emisión de GEI para el arroz Uruguayo.

Resulta de gran importancia continuar evaluando los procesos que controlan los flujos de emisión de GEI en el cultivo, utilizan- do tecnologías que disminuyan el consumo de agua, manteniendo la productividad del arroz, en búsqueda de un desarrollo del cultivo ambientalmente sustentable.

\section{AGRADECIMIENTOS}

M. Oxley, I. Furtado, A. Rodriguez, G. Rodriguez, B. Mesones, A. Martinez, F. Franco, S. Latorre y L. Pinelli por su colaboracion con el trabajo de campo y laboratorio.

\section{BIBLIOGRAFÍA}

BAKKEN, L.; BERGAUST, L.; LIU, B.; FROSTEGARD, A. 2012. Regulation of denitrification at the cellular level: a clue to the understanding of $\mathrm{N}_{2} \mathrm{O}$ emissions from Soils. Philosophical Transactions of the Royal Society of London: Series B, Biological Sciences. Vol. 367 (1593). P. 1226-1234.

BAKKEN, L.; DORSCH, P. 2007. Nitrous Oxide Emission and Global Changes: Modeling Approaches. Biology of the Nitrogen Cycle. Chapter 25 in Biology of the Nitrogen Cycle, Bothe $\mathrm{H}$, Ferguson SJ, Newton WE (eds).pp 382-395. Elsevier (Amsterdam).

BARUAH, K., GOGOI, B., GOGOI, P. 2010. Plant physiological and soil characteristics associated with methane and nitrous oxide emission from rice paddy. Physiology and Molecular Biology of Plants, Vol. 16, N 1 . P. 79-91.

BECOÑA, G.; ORDEIG, L. 2013. Huella del carbono y comercio exterior en Uruguay: informe de consultoría. Montevideo, Instituto Uruguay XXI. Disponible enhttp:/ /www.uruguayxxi.gub.uy/wp-content/ uploads/2013/08/Informe-Huella-deCarbono.pdf.

BECOÑA, G.; OYANTCABAL, W.; ASTIGARRAGA, L.; ROEL, A.; SAIZAR, C. 2014. Primer Estudio de la Huella de Carbono de Tres Cadenas Agroexportadoras del Uruguay: Carne vacuna, Lácteos y Arroz. Informe Final. Ministerio de Ganadería Agricultura y Pesca, Facultad de Agronomía, Instituto Nacional de Investigación Agropecuaria, Laboratorio Tecnológico del Uruguay. $61 p$. 
BOWDEN, R.; MELILLO, J.; STEUDLER, P.; ABER, J. 1990. Annual nitrous oxide fluxes from temperate forest soils in the northeastern United States. Journal of Geophysical Research. Vol.95. P. 1399714005.

BOUMAN, B.; TUONG, T. 2001. Field water management to save water and increase its productivity in irrigated lowland rice. Agricultural Water Management. 49. P. 11-30.

CAI, Z.; XING, G.; YAN, X.; XU, H.; TSURUTA, H.; YAGI, K.; MINAMI, K. 1997. Methane and nitrous oxide emissions from rice paddy fields as affected by nitrogen fertilizers and water management. Plant and Soil. Vol. 196. P. 7-14.

CARLSSON-KANYAMA, A.; GONZÁLEZ, A. 2007. Non- $\mathrm{CO}_{2}$ greenhouse gas emissions associated with food production: methane $\left(\mathrm{CH}_{4}\right)$ and nitrous oxide $\left(\mathrm{N}_{2} \mathrm{O}\right)$. Disponible en:<http://www.ima.kth.se/ e $n g / r$ e $s$ p u b l i c / emissions_report_17_set_ACK.pdf> Acceso en: 7 de agosto, 2012.

CHAPAGAIN, T.; YAMAJI, E. 2010. The effects of irrigation method, age of seedling and spacing on crop performance, productivity and water-wise rice production in Japan. Paddy Water Environment. Vol. 8 (1). P. 81-90.

CHEN, G.; HUANG, G.; SHANG, S.; LI, N.; WU, J.; YU, K.; , XU, H.; WANG, Y.; LI, L. 1992. Measurement of $\mathrm{N}_{2} \mathrm{O}$ emission from soil, plants and soil-plant systems. In Ghazi A (ed.). Proceedings of CEC and P. R. China workshop of contribution to global change. Biosphere atmosphere interactions. Brussels Belgium. P. 109-114.

CICERONE, R.; DELWICHE, C.; TYLER SC, ZIMMERMAN, P. 1992. Methane emissions from California rice paddies with varied treatments. Global Biogeochemical Cycles. Vol.6(3). P. 233-248.

CONRAD, R. 2002. Control of microbial methane production in wetland rice fields. Nutrient Cycling in Agroecosystems. Vol. 64. P. 59-69.

DALAL, R.; WANG, W; ROBERTSON, G.; PARTON, W. 2003. Nitrous oxide emissions from Autralian agricultural lands and mitigation options: a review. Australian Journal of Soil Rerearch. Vol. 41. P. 165-195.
DEAMBROSI, E. 2007. Rice production situation in Uruguay. International Rice Commission Newsletter. FAO, Roma. P. 84-86.

DENMEAD, O. 1979. Chamber systems for measuring nitrous oxide emission from soils in the field. Soil Science Society of America Journal. Vol. 43. P.89-95.

FAO N56. Guía para la determinación de los requerimientos de agua de los cultivos. Estudio FAO Riego y Drenaje $N^{\circ} 56$. $298 p$.

FRENEY, J.; DENMEAD, O.; WATANABE, I.; CRASWELL, E. 1981. Ammonia and nitrous oxide losses following applications of ammonium sulfate to flooded rice. Australian Journal of Agricultural Research. Vol. 32. P. 37-45.

FREIRE MOTERLE, D.; SOUZA DA SILVA, L.; MORO, V.; BAYER, C. 2013. Methane efflux in rice paddy field under different irrigation managements. R Bras Ci Solo 37:431-437

FROHMANN, A.; OLMOS, X. 2013. Huella de Carbono, exportaciones y estrategias empresariales frente al Cambio Climático. Comisión Económica para América Latina y el Caribe - CEPAL. 77P.

GARCIA-PRÉCHAC, F.; ERNST, O.; SIRI-PRIETO, G.; TERRA, J. 2004. Integrating no-till into crop-pasture rotations in Uruguay. Soil and Tillage Research. Vol. 77. P. 1-13.

GEYMONAT, E.; FERRANDO, L.; TARLERA, S. 2011. Methylogaea oryzae gen .nov., sp. nov., a novel mesophilic methanotroph from a rice paddy field in Uruguay. International Journal of Systematic and Evolutionary Microbiology. Vol. 61. P. 2568-2572.

GRANLI, T.; BOCKMAN, O. 1994. Nitrous oxide from agriculture. Norwegian Journal of Agricultural Sciences Supplement. Vol.12. P. 7-128.

GUO, J.; ZHOU, C. 2007. Greenhouse Gas Emissions and mitigation measures in Chinese Agroecosystems. Agricultural and Forest Meteorology. Vol. 142. P. 270-277.

GUO, X.; DRURY, C.; ZHANG, R. 2010. Influence of constant and Fluctuating Water Contents on Nitrous Oxide Emissions from Soils under Variyng Crop Rotations. Soil Science Society of America Journal. Vol. 74. P. 2077-2085. 
HADI, A.; INUBISHI, K.; YAGI, K. 2010. Effect of water management on greenhouse gas emissions and microbial properties of paddy soils in Japan and Indonesia. Paddy Water Environment. Vol. 8. P.319-324.

IAEA (International Atomic Energy Agency). 1992. Methane and nitrous oxide flux measurements from soil and plant systems. In Manual of measurement of methane and nitrous oxide emissions from agriculture. IAEA-TECDOC-674. Internacional Atomic Energy Agency, Vienna, Austria. Vienna, Austria, p. 45-89.

IRISARRI, P.; GONNET, S.; DEAMBROSI, E.; MONZA, J. 2007. Cyanobacterial inoculation and nitrogen fertilization in rice. World of Microbiology and Biotechnology. Vol. 23. P. 237-242.

IRISARRI, P.; TARLERA, S.; FERNÁNDEZ, A.; PEREIRA, V.; URRABURU, M.; TERRA, J. 2010. Arroz y gases de efecto invernadero. Revista Arroz $\mathrm{N}^{\circ} 62$. Disponible en:<http://www.aca.com.uy> Acceso en: 7 de agosto, 2012.

IPCC. Grupo Intergubernamental de Expertos sobre el Cambio Climático. 2007: Cambio climático 2007: Informe de síntesis. Contribución de los Grupos de trabajo I, II y III al Cuarto Informe de evaluación del Grupo Intergubernamental de Expertos sobre el Cambio Climático [Equipo de redacción principal: Pachauri, R.K. y Reisinger, A. (directores de la publicación)]. IPCC, Ginebra, Suiza, $104 \mathrm{p}$.

ITOH, M.; SUDO, S.; MORI, S.; SAITO, H.; YOSHIDA, T; SHIRATORI, Y.; SUGA, S.; YOSHIKAWA, N.; SUZUE, Y.; MIZUKAMI, H.; MOCHIDA, T.; YAGI, K. 2011. Mitigation of methane emissions from paddy fields by prolonging midseason drainage. Agriculture, Ecosystems and environment. Vol. 141. P. 359-372.

JACOBSON, M. 2005. Atmospheric pollution: history, science and regulation. Cambridge University Press, New York.

JAIN, N.; DUBEY, R.; DUBEY, D.; SINGH, J. 2013. Mitigation of greenhouse gas emission with system of rice intensification in the IndoGangetic Plains. Paddy Water Environment. doi:10.1007/s1033301303902.

JOHNSON-BEEBOUT, S.; ANGELES, O.; ALBERTO, M.; BURESH, R. 2009. Simultaneous minimization of nitrous oxide and methane emission from rice paddy soils is improbable due to redox potential changes with depth in a greenhouse experiment without plants. Geoderma. Vol. 149. P. 45-53.

KHALIL, M.; BAGGS, E. 2005. Methane oxidation and Nitrous Oxide emissions at varied soil water-filled pore spaces and headspace Methane concentrations.Soil Biology and Biochemestry. Vol. 37. P. 1785-1794.

LI, D.; LIU, M.; CHENG, Y.; WANG, D.; QIN, J.; JIAO, J.; LI, H.; HUA, F. 2011. Methane emissions from double-rice cropping system under conventional and no tillage in southeast China. Soil and Tillage Research. Vol. 113. P. 77-81.

LINDAU, C.; BOLLICH, P.; DELAUNE, R.; PATRICK, W.; LAW, V. 1991. Effect of urea fertilizer and environmental factors on $\mathrm{CH}_{4}$ emissions from a Louisiana, USA, rice field. International Journal of Plant and Soil Science. Vol. 136. P. 195-203.

LINQUIST, B.; VAN GROENIGEN, K.; ADVIENTOBORBE, M.; PITTELKOW, C.; VAN KESSEL, C. 2012. An agronomic assessment of greenhouse gas emissions from major cereal crops. Global Change Biology. Vol. 18. P.194-209.

MATSON, P.; NAYLOR, R.; ORTIZ-MONASTERIO, I. 1998. Integration of Environmental, Agronomic and Economic Aspects of Fertilizer Management. Science. Vol. 280. P. 112-114.

MÉNDEZ, R.; DEAMBROSI, E. 2003. Efectos de la anticipación de la aplicación del glifosato para la siembra de arroz con cero laboreo en la zona Este de Uruguay. En: Proceedings of the III International Conference of Temperate Rice; Punta del Este, Uruguay. Montevideo: INIA. p. 65.

MINODA, T.; KIMURA, M. 1994. Contribution of photosynthesized carbon to the methane emitted from paddy fields. Geophysical Research Letters. Vol. 21 (18). P. 20072010.

MINAMIKAWA, K.; SAKAI, N. 2006. The practical use of water management based on soil redox potential for decreasing methane emissions from a paddy field in Japan. Agriculture, Ecosystems and Environment. Vol. 116. P. 181-188. 
MINAMIKAWA, K.; YAGI, K.; TOKIDA, T.; SANDER, B.; WASSMANN, R. 2012. Appropiate frequency and time of day to measure methane emissions from an irrigated rice paddy in Japan using the manual closed chamber method. Greenhouse Gas Measurement and Management. Vol. 2. P. 118-128.

MINISTERIO DE GANADERÍA AGRICULTURA Y PESCA - ESTADÍSTICAS AGROPECUARIAS (DIEA-MGAP). 2012. Anuario Estadístico Agropecuario 2012. $244 p$.

MINISTERIO DE VIVIENDA ORDENAMIENTO TERRITORIAL Y MEDIO AMBIENTE, DIRECCIÓN NACIONAL DEL MEDIO AMBIENTE, UNIDAD DE CAMBIO CLIMÁTICO. 2010. Tercera Comunicación Nacional a la Conferencia de las partes en la Convención Marco de las Naciones Unidas sobre el Cambio Climático. Proyecto URU/05/G32.

MISHRA, S.; RATH, A.; ADHYA, T.; RAO, V.; SETHUNATHAN, N. 1997. Effect of continuos and alternate water regimes on methane efflux from rice under greenhouse conditions. Biology and Fertility of Soils. Vol. 24, N 4. P. 399405.

MITRA, S.; AULAKH, M.; WASSMANN, R.; OLK, D. 2005. Triggering of methane production in rice soils by root exudates: effects of soil properties and crop management Soil Science Society of America Journal. Vol. 69. P. 563-570.

NEUE, H. 1997. Fluxes of methane from rice fields and potential for mitigation. Soil Use and Managemetat. Vol. 13. P. 258-267.

NOUCHI, I.; MARIKO, S.; AUKI, K. 1990. Mechanism of methane transport from the rhizosphere to atmosphere through rice plants. Plant Physiology. Vol. 94 (1). P. 59-66.

OYHANTÇABAL, W. 2010. El MGAP y la «huella» de carbono de productos de exportación: una estrategia en defensa de la competitividad. 6 p. In Uruguay. Ministerio de Ganadería Agricultura y Pesca. Montevideo, MGAP. Disponible en http://www.mgap.gub.uy/portal/ agxppdwn.aspx?7,1,39,O,S,0,4482\%3BS \%3В2\%3B96.

PENG, S.; BOUMAN, B. 2007. Prospects for genetic improvement to increase lowland rice yields whith less water and nitrogen. In: Spiertz, J.H.J., Struik, P.C. van Laar, H.H. (Eds.) Scale and Complexity in Plant Systems Research: Gene-Plant-Crop Relations. P. 251-266.

PENG, S.; YANG, S.; XU, J.; GAO, H. 2011. Field experiments on greenhouse gas emissions and nitrogen and phosphorus losses from rice paddy with efficient irrigation and drainage management. Science China Technological Sciences. Vol. 54 (6). P. 1581-1587.

PEREYRA, V. 2009. Emisiones de metano y óxido nitroso en arrozales de la zona este del Uruguay: el manejo de cultivo como factor determinante. Pasantía de grado de la Licenciatura en Ciencias Biológicas. Profundización en Biotecnología. Facultad de Química-Facultad de Ciencias. UDELAR. $40 \mathrm{p}$.

PERDOMO, C.; IRISARRI, P.; ERNST, O. 2009. Nitrous oxide emissions from an uruguayan argiudoll under different tillage and rotation treatments Nutrient Cycling in Agroecosystems. Vol. 84. P. 119-128.

PITTELKOW, C.; ADVIENTO-BORBE, M.; HILL, J. 2013. Yield-scaled global warming potential of annual nitrous oxide and methane emissions from continuously flooded rice in response to nitrogen input Agricuture, Ecosystems and Environment. Vol. 177. P. 10-20.

ROEL, A.; FIRPO, H.; PLANT, R. 2007. Why do some farmers get higher yields? Multivariate analysis of a group of Uruguayan rice farmers. Computers and electronics in agriculture. Vol. 58. P. 78-92.

ROGERS, C.; BRYE, K.; NORMAN, R.; GASNIER, T.; FRIZZELL, D.; BRANSON, J. 2012. Methane Emissions from a Silt-Loam Soil Under Direct- Seeded, DelayedFlood Rice Management. In: Norman R J, Moldenhauer KAK (eds) University of Arkansas Agricultural Experiment Station Research Series 600, Fayetteville, AR. P 240-247.

SASS, R.; FISHER, F.; WANG, B. 1992. Methane emission from rice fields: the effect of floodwater management. Global Biochemical Cycles. Vol. 6. $\mathrm{N}^{\circ} 3$, p. 249262. 
SCHULTZ, H.; HOLZAPEL-PSCHORN, A.; CONRAD, R.; RENNENBERG, H.; SEILER, W. 1989. A three-year continuous record on the influence of daytime season and fertilizer treatment on methane emission rates from an Italian rice paddy field. Journal of Geophysical Research. Vol. 94. P. 16405-16416.

SHIRATORI, Y.; WATANABE, H.; FURUKAWA, Y.; TSURUTA, H.; INUBUSHI, K. 2007. Effectiveness of a subsurface drainage system in poorly drained paddy fields on reduction of methane emissions. Soil Science and Plant Nutrition, Vol. 53(4). P. 387-400.

SKIBA, U.; BALL, B. 2002. The effect of soil texture and soil drainage on emissions of nitric oxide and nitrous oxide. Soil Use and Management. Vol. 18. P. 56-60.

SMITH, C.; BRANDON, M.; PATRICK JR., W. 1982. Nitrous oxide emission following Urea-N fertilization of wetland rice. Soil Science and Plant Nutrition. Vol.28. P. 161-171.

SMITH, P.; MARTINO, D.; CAI, Z.; GWARY, D. 2007. Agriculture. In: Metz B, Davidson O R, Bosch P R, Dave R, Meyer L A (eds) Climate Change: Mitigation. Contribution of Working Group III to the Fourth Assessment Report of the Intergovernmental Panel on Climate Change. Cambridge, Cambridge University Press. P 497-540.

TABBAL, D.; BOUMAN, B.; BHUIYAN, S.; SIBAYAN, E.; SATTAR, M. 2002. On-farm strategies for reducing water input in irrigated rice; case studies in the Philippines. Agricultural Water Management. 56. P. 93-112.

THAKUR, A.; RATH, S.; PATIL, D.; KUMAR, A. 2011. Effects on rice plant morphology and physiology of water and associated management practices of the system of rice intensification and their implications for crop performance. Paddy Water Environment. Vol. 9. P. 13-24.

TOWPRAYOON, S.; HARVEY, N.; JITTASATRA, O.; KERDCHUCHEAN, O. 2000. Influence of rice variety and soil type on production and emission of methane from rice fields. Asian Journal of Energy and Environment. Vol.1. P. 251-62.

TOWPRAYOON, S.; SMAKGAHN, K.; POONKAEW, S. 2005. Mitigation of methane and nitrous oxide emissions from drained irrigated rice fields. Chemosphere. Vol. 59. P.1547-1556.

TYAGI, L.; KUMARI, B.; SINGH, S. 2010. Water management - A tool for methane mitigation from irrigated paddy fields. Science of the Total Environment. Vol. 408. P.1085-1090.

UNITED STATES DEPARTMENT OF AGRICULTURE. 2010. Keys to Soil Taxonomy, $11^{\text {th }}$ edn. USDA, USA. 338p.

VIBOL, S.; TOWPRAYOOM, S. 2010. Estimation of methane and nitrous oxide emissions from rice field with rice straw management in Cambodia. Environmental Monitoring and Assessment. Vol. 161. P. 301-313.

WANG, Z.; LINDAU, C.; DELAUNE, R.; PATRICK, W. 1993. Methane emission and entrapment in flood rice solis as affected by soil properties. Biology and Fertility of Soils. Vol. 16. P. 163-168.

WASSMANN, R.; AULAKH, M.; LANTIN, R.; RENNENBERG, H.; ADUNA, J. 2002. Methane emission patterns for rice fields planted to several cultivars for nine seasons. Nutrient Cycling and Agroecosystems. Vol. 64. P. 111-124.

WATANABE, A.; TAKEDA, T.; KIMURA, M. 1999. Evaluation of origins of $\mathrm{CH}_{4}$ carbon emitted from rice paddies. Journal of Geophysical Research. Vol. 104(19). P. 23623-23629.

WIEDMANN, T.; MINX, J. 2007. A definition of 'Carbon Footprint'. Research Report 0701. ISA UK Research an Consulting. 9p.

XU, S.R.; JAFFE, P.; MAUZERALL, D.L. 2007. A process-based model for methane emission from flooded rice paddy systems. Ecol Model 205(3-4):475-91.

YAGI, K.; TSURUTA, H.; KANDA, K.; MINAMI, K. 1996. Effect of water management on methane emission from a Japanese paddy field: automated methane monitoring. Global Biogeochemical Cycles. Vol.10(2). P. 255-267.

YAN, X.; YAGI, K.; AKIYAMA, H.; AKIMOTO, H. 2005. Statistical analysis of the major variables controlling methane emission from rice fields. Global Change Biology. Vol. 11. P. 1131-1141.

YAO, F.; HUANG, J.; CUI, K.; NIE, L; XIANG, J.; LIU, X; WU, W; CHEN, M; PENG, S. 2011. Agronomic performance of high-yielding 
rice variety grown under alternate wetting and drying irrigation. Field Crops Research. Vol. 126. P. 16-22.

HANG, G.; ZHANG, X.; MA, J.; XU, H.; CAI, Z. 2011. Effect of drainage in the fallow season on reduction of $\mathrm{CH} 4$ production and emission from permanently flooded rice fields. Nutrient Cycling in Agroecosystems. Vol. 89.P. 81-91.

ZHAO, X.; MIN, J.; WANG, S.; SHI, W.; XING, G. 2011. Further understanding of nitrous oxide emission from paddy fields under rice/wheat rotation in South China.
Journal of Geophysical Research. Vol. 116. G02016.

ZOU, J.; HUANG, Y.; JIANG, J.; ZHENG, X.; SASS, R. 2005. A three year field measurement of methane and nitrous oxide emissions from rice paddies in China: effects of water regime, crop residue, and fertilizer application. Global Biogeochemical Cycles. Vol. 19. P. 2021.

ZOU, J.; HUANG, Y.; ZHENG, X.; WANG, Y. 2007. Quantifying direct $\mathrm{N}_{2} \mathrm{O}$ emissions in paddy fields during rice growing season in mainland China: dependence on water regime. Atmospheric Environment. Vol. 41. P. 8030-8042. 

ANEXOS 
Cuadro 1. Calendario Agronómico para la Zafra 1.

\begin{tabular}{|c|c|c|}
\hline Fecha & Práctica Agronómica & Detalles \\
\hline $8 / 10 / 2010$ & Siembra y fertilización & $\begin{array}{l}\text { Variedad: El Paso } 144 \text { - } 154 \mathrm{~kg} / \mathrm{ha} \\
182 \mathrm{~kg} / \mathrm{ha} \text { de } 9-36-10\left(\mathrm{~N}_{16} \mathrm{P}_{66} \mathrm{~K}_{18}\right)\end{array}$ \\
\hline $10 / 11 / 2010$ & Emergencia del cultivo & \\
\hline $30 / 10 / 2011$ & Aplicación de herbicida & \\
\hline $19 / 11 / 10$ & Aplicación de herbicida & $\begin{array}{l}\text { Facet 1,5 L/ha + Propanil } 3 \mathrm{~L} / \mathrm{ha}+\text { Command 0,85 L/ha } \\
+ \text { Cyperex } 200 \mathrm{~g} / \mathrm{ha}\end{array}$ \\
\hline $13 / 12 / 10$ & & Macollaje: 60 kg/ha de urea \\
\hline $\begin{array}{l}\text { IC30:03/01/11 } \\
\text { RR:13/1/11 }\end{array}$ & Fertilización & Primordio floral: $50 \mathrm{~kg} / \mathrm{ha}$ de urea ${ }^{* *}$ \\
\hline $\begin{array}{l}\text { IC30:13/12/10 } \\
\text { RR:13/1/11 }\end{array}$ & Inundación & \\
\hline
\end{tabular}

${ }^{*}$ Aplicación de Urea con suelo seco: previo a la inundación en el tratamiento IC30, y previo al primer riego en el tratamiento RR.

Cuadro 2. Calendario Agronómico para la Zafra 2.

\begin{tabular}{|c|c|c|}
\hline Fecha & Práctica Agronómica & Detalles \\
\hline $22 / 10 / 2011$ & Siembra y fertilización & $\begin{array}{l}\text { Variedad: El Paso } 144 \text { - } 146 \mathrm{~kg} / \mathrm{ha} \\
184 \mathrm{~kg} / \mathrm{ha} \text { de } 9-40-13\left(\mathrm{~N}_{16} \mathrm{P}_{66} \mathrm{~K}_{18}\right)\end{array}$ \\
\hline $9 / 11 / 2011$ & Emergencia del cultivo & \\
\hline $30 / 10 / 2011$ & Aplicación de herbicida & Clomazone 0,8 L/ha. \\
\hline 22/11/11 & Aplicación de herbicida & Quinclorac 1,5 L/ha + Propanil 3 L/ha + Cyperof 50 g/ha \\
\hline 9/12/11 & & Macollaje: $60 \mathrm{~kg} / \mathrm{ha}$ de urea \\
\hline $\begin{array}{l}\text { IC30:6/1/12 } \\
\text { RR:20/1/12 }\end{array}$ & Fertilización & Primordio floral: $60 \mathrm{~kg} / \mathrm{ha}$ de urea ${ }^{* *}$ \\
\hline $\begin{array}{l}\text { IC30:9/12/11 } \\
\text { RR:20/1/12 }\end{array}$ & Inundación & \\
\hline
\end{tabular}

${ }^{*}$ Aplicación de Urea con suelo seco: previo a la inundación en el tratamiento IC30, y previo al primer riego en el tratamiento RR.

Cuadro 3. Calendario Agronómico para la Zafra 3.

\begin{tabular}{|c|c|c|}
\hline Fecha & Práctica Agronómica & Detalles \\
\hline $19 / 10 / 2012$ & Siembra y fertilización & $\begin{array}{l}\text { Variedad: El Paso } 144-140 \mathrm{~kg} / \mathrm{ha} \\
166 \mathrm{~kg} / \mathrm{ha} \text { of 8-39-15 }\left(\mathrm{N}_{16} \mathrm{P}_{66} \mathrm{~K}_{18}\right)\end{array}$ \\
\hline $3 / 11 / 2012$ & Emergencia del cultivo & \\
\hline $12 / 11 / 2012$ & Aplicación de herbicida & Ricer $150 \mathrm{ml} / \mathrm{ha}+$ Clomazone $0,8 \mathrm{l} / \mathrm{ha}+$ Cyperof $60 \mathrm{~g} / \mathrm{ha}$ \\
\hline 29/11/11 & Aplicación de herbicida & Quinclorac 1,3 L/ha + Propanil 5 L/ha. \\
\hline $3 / 12 / 12$ & & Macollaje: $60 \mathrm{~kg} / \mathrm{ha}$ de urea \\
\hline $\begin{array}{l}\text { IC } 30: 28 / 12 / 12 \\
\text { RR: } 7 / 1 / 13\end{array}$ & Fertilización & Primordio floral: $60 \mathrm{~kg} / \mathrm{ha}$ de urea ${ }^{* *}$ \\
\hline $\begin{array}{l}\text { IC30:3/12/12 } \\
\text { RR: } 7 / 1 / 13\end{array}$ & Inundación & \\
\hline
\end{tabular}

${ }^{*}$ Aplicación de Urea con suelo seco: previo a la inundación en el tratamiento IC30, y previo al primer riego en el tratamiento RR. 
Cuadro 4. Riegos aplicados en la Zafra 1.

\begin{tabular}{|c|c|c|c|c|}
\hline \multirow{2}{*}{ Trat. } & \multicolumn{2}{|c|}{ Baños* $^{*}$} & \multicolumn{2}{c|}{ Riegos intermitentes } \\
\cline { 2 - 5 } & Fecha & Volumen (mm) $^{*}$ Fecha & Volumen (mm) \\
\hline \multirow{4}{*}{ IC30 } & 25 Oct (-16 DDE) & 54 & -- & --- \\
& 8 Nov (-2 DDE) & 65 & -- & \\
& 26 Nov (16 DDE) & 68 & 13 Dic (33 DDE) & 29 \\
& & & 21 Dic (41 DDE) & 44 \\
& & & 27 Dic (47 DDE) & 32 \\
RR & 25 Oct (-16 DDE) & 69 & 3 Enero (54 DDE) & 39 \\
& 8 Nov (-2 DDE) & 72 & 7 Enero (58 DDE) & 36 \\
& 26 Nov (16 DDE) & 68 & 10 Enero (61 DDE) & 79 \\
& & & & \\
\hline
\end{tabular}

*Baños previos a la inundación.

Cuadro 5. Riegos aplicados en la Zafra 2.

\begin{tabular}{|l|c|c|c|c|}
\hline \multirow{2}{*}{ Trat. } & \multicolumn{2}{|c|}{ Baños* $^{*}$} & \multicolumn{2}{c|}{ Riegos intermitentes } \\
\cline { 2 - 5 } & Fecha & Volumen (mm) $^{\prime}$ & Fecha & Volumen (mm) \\
\hline IC30 & 23 Nov (14 DDE) & 79 & ---- & --- \\
\hline \multirow{4}{*}{ RR } & & & 9 Dic. (30 DDE) & 74 \\
& \multirow{3}{*}{23 Nov (14 DDE) } & \multirow{2}{*}{92} & 30 Dic. (51 DDE) & 58 \\
& & & 3 Enero (55 DDE) & 17 \\
& & & 5 Enero(57 DDE) & 20 \\
& & & 13 Enero (61 DDE) & 24 \\
& & & 17 Enero(65 DDE) & 23 \\
\hline
\end{tabular}

*Baños previos a la inundación.

Cuadro 6. Riegos aplicados en la Zafra 3.

\begin{tabular}{|l|c|c|}
\hline \multirow{2}{*}{ Trat. } & \multicolumn{2}{|c|}{ Riegos intermitentes } \\
\cline { 2 - 3 } & Fecha & Volumen $(\mathbf{m m})$ \\
\hline IC30 & ---- & --- \\
\hline \multirow{2}{*}{ RR } & 3 Dic. (30 DDE) & 95 \\
& 24 Dic. (51 DDE) & 56 \\
\hline
\end{tabular}

Cuadro 7. Heliofanía promedio en torno al periodo crítico del cultivo (+/- 20 días del 50\% de floración) para la Zafra 1.

\begin{tabular}{|c|c|c|}
\hline Tratmiento & $\begin{array}{c}\text { Horas de sol } \\
(\mathbf{2 0 1 0 / 2 0 1 1 )}\end{array}$ & $\begin{array}{c}\text { Horas de sol S.H } \\
(\mathbf{1 9 7 3 / 2 0 1 0 )}\end{array}$ \\
\hline IC30 & 7,9 & 7,7 \\
\hline RR & 7,8 & 7,6 \\
\hline
\end{tabular}

S.H.: Serie Histórica. 


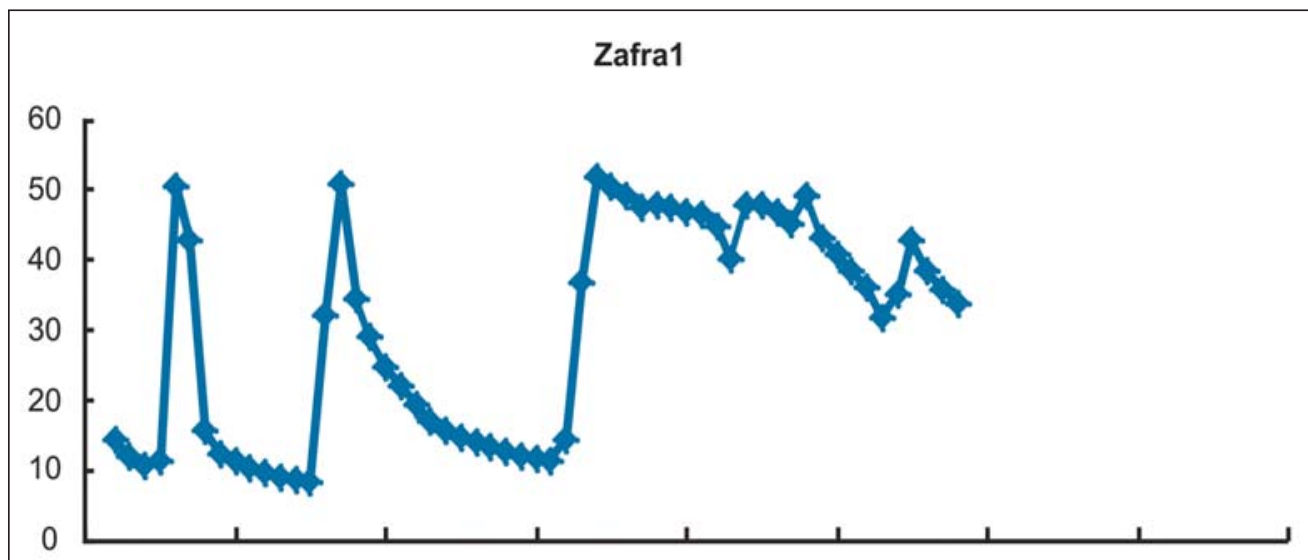

Zafra 2

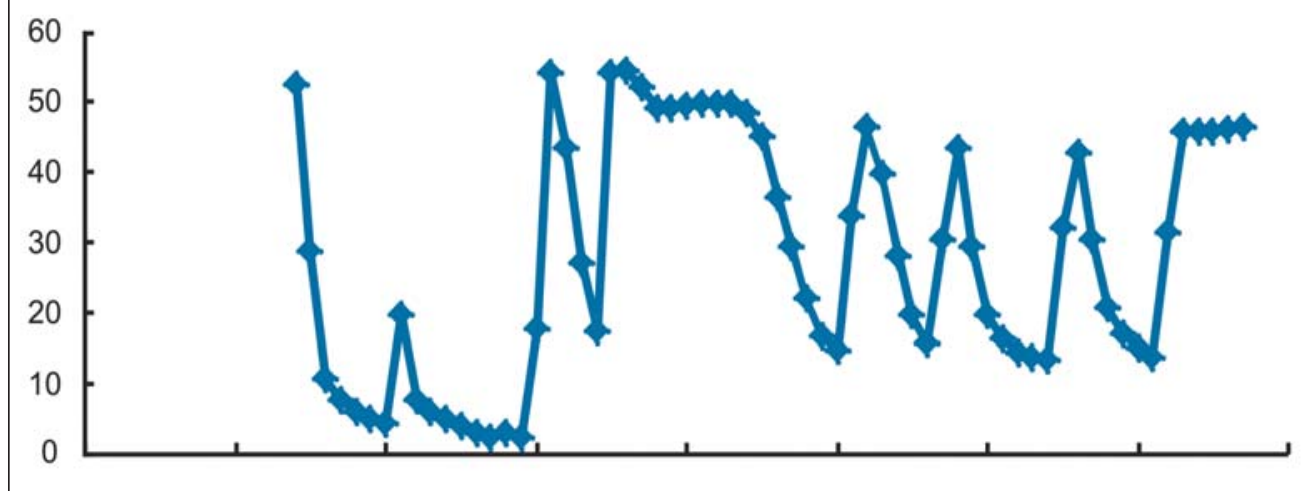

Zafra 3

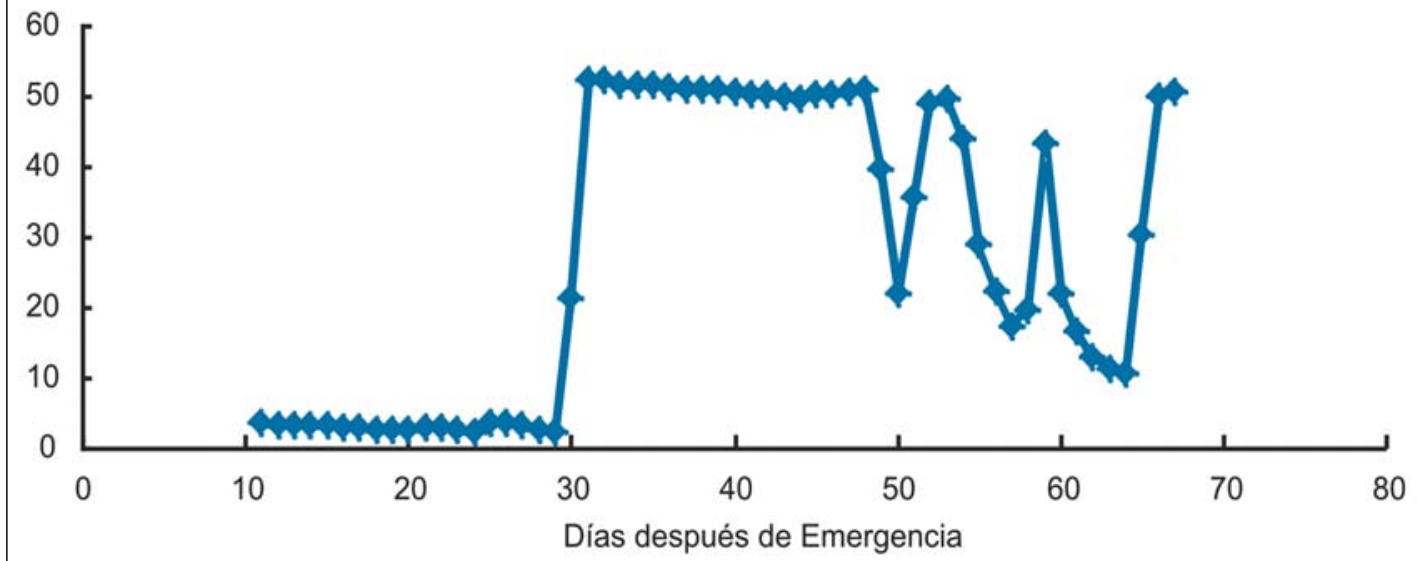

$\longrightarrow$ Contenido de agua en el suelo $(\mathrm{mm})$

Figura 1. Evolución del contenido de agua en el suelo en el tratamiento RR para las tres zafras. 
Cuadro 8. Heliofanía promedio en torno al periodo crítico del cultivo (+/- 20 días del 50\% de floración) para la Zafra 2.

\begin{tabular}{|c|c|c|}
\hline Tratamiento & $\begin{array}{c}\text { Horas de sol } \\
(\mathbf{2 0 1 1 / 2 0 1 2 )}\end{array}$ & $\begin{array}{c}\text { Horas de sol S.H. } \\
(\mathbf{1 9 7 3 / 2 0 1 1 )}\end{array}$ \\
\hline IC30 & 6,8 & 7,6 \\
\hline RR & 6,2 & 7,4 \\
\hline
\end{tabular}

S.H.: Serie Histórica.

Cuadro 9. Heliofanía promedio en torno al periodo crítico del cultivo (+/- 20 días del $50 \%$ de floración) para la Zafra 3.

\begin{tabular}{|c|c|c|}
\hline Tratamiento & $\begin{array}{c}\text { Horas de sol } \\
(\mathbf{2 0 1 1 / 2 0 1 2 )}\end{array}$ & $\begin{array}{c}\text { Horas de sol S.H. } \\
(\mathbf{1 9 7 3 / 2 0 1 1 )})\end{array}$ \\
\hline IC30 & 8,0 & 7,8 \\
\hline RR & 7,9 & 7,7 \\
\hline
\end{tabular}

S.H.: Serie Histórica.

Cuadro 10. Temperatura mínima y temperatura media promedio en torno al período crítico del cultivo (+/- 20 del 50\% de floración) para la Zafra 1.

\begin{tabular}{|c|c|c|c|c|}
\hline Tratamiento & $\begin{array}{c}\text { Temp. Min. } \\
(\mathbf{2 0 1 0 / 2 0 1 1 )}\end{array}$ & $\begin{array}{c}\text { Temp. Min } \\
\text { S.H.(1973/2010) }\end{array}$ & $\begin{array}{c}\text { Temp. media } \\
\mathbf{( 2 0 1 0 / 2 0 1 1 )}\end{array}$ & $\begin{array}{c}\text { Temp. media S.H. } \\
\mathbf{( 1 9 7 3 / 2 0 1 0 )}\end{array}$ \\
\hline IC30 & 17,1 & 16,1 & 23,2 & 22,2 \\
\hline RR & 16,8 & 15,7 & 22,9 & 22,0 \\
\hline
\end{tabular}

S.H.: Serie Histórica.

Cuadro 11. Temperatura mínima y temperatura media promedio en torno al período crítico del cultivo (+/- 20 del 50\% de floración) para la Zafra 2.

\begin{tabular}{|c|c|c|c|c|}
\hline Tratamiento & $\begin{array}{c}\text { Temp. } \min \\
(\mathbf{2 0 1 1 / 2 0 1 2 )}\end{array}$ & $\begin{array}{c}\text { Temp. min S.H. } \\
\mathbf{( 1 9 7 3 / 2 0 1 1 )}\end{array}$ & $\begin{array}{c}\text { Temp. Media } \\
\mathbf{( 2 0 1 1 / 2 0 1 2 )}\end{array}$ & $\begin{array}{c}\text { Temp. Media S.H } \\
(\mathbf{1 9 7 3 / 2 0 1 1 )}\end{array}$ \\
\hline IC30 & 17,8 & 16,9 & 23,6 & 22,7 \\
\hline RR & 18,9 & 16,7 & 24,1 & 22,5 \\
\hline
\end{tabular}

S.H.: Serie Histórica.

Cuadro 12. Temperatura mínima y temperatura media promedio en torno al período crítico del cultivo (+/- 20 del 50\% de floración) para la Zafra 3.

\begin{tabular}{|c|c|c|c|c|}
\hline Tratamiento & $\begin{array}{c}\text { Temp. } \text { min } \\
(\mathbf{2 0 1 2 / 2 0 1 3 )}\end{array}$ & $\begin{array}{c}\text { Temp. minS.H. } \\
\mathbf{( 1 9 7 3 / 2 0 1 1 )}\end{array}$ & $\begin{array}{c}\text { Temp. media } \\
\mathbf{( 2 0 1 2 / 2 0 1 3 )}\end{array}$ & $\begin{array}{c}\text { Temp. media S.H. } \\
\mathbf{( 1 9 7 3 / 2 0 1 1 )}\end{array}$ \\
\hline IC30 & 16,6 & 16,9 & 22,3 & 22,8 \\
\hline RR & 16,7 & 16,9 & 22,3 & 22,8 \\
\hline
\end{tabular}

S.H.: Serie Histórica. 
Impreso en Editorial Hemisferio Sur S.R.L.

Buenos Aires 335

Montevideo - Uruguay

Depósito Legal 366-657/15 
INIA Dirección Nacional

Andes 1365, P. 12

Montevideo

Tel.: 59829020550

Fax: 59829023633

iniadn@dn.inia.org.uy

INIA La Estanzuela

Ruta 50, Km 11

Colonia

Tel.: 59845748000

Fax: 59845748012

iniale@le.inia.org.uy

INIA Las Brujas

Ruta 48, Km 10

Canelones

Tel.: 59823677641

Fax: 59823677609

inia_lb@lb.inia.org.uy

INIA Salto Grande

Camino al Terrible

Salto

Tel.: 59847335156

Fax: 59847329624

inia_sg@sg.inia.org.uy

INIA Tacuarembó

Ruta 5, Km 386

Tacuarembó

Tel.: 59846322407

Fax: 59846323969

iniatbo@tb.inia.org.uy

INIA Treinta y Tres

Ruta 8, Km 281

Treinta y Tres

Tel.: 59844522023

Fax: 59844525701

iniatt@tyt.inia.org.uy

www.inia.uy 